\section{RevistadePolítica Económica y Desarrollo Sostenible}

Centro Internacional de Política Económica para el Desarrollo Sostenible
Revista de Política Económica y Desarrollo Sostenible

EISSN: 2215-4167 • Vol. 7 (1) • Julio-Diciembre, 2021: 1-34

DOI: https://doi.org/10.15359/peds.7-1.1

URL: http://www.revistas.una.ac.cr/politicaeconomica

Revista electrónica semestral publicada por el Centro Internacional de Política Económica para el Desarrollo Sostenible

Universidad Nacional, Lagunilla, Heredia Apartado 2393-3000

\title{
La dinamización de cadenas agroindustriales uruguayas en contexto de expansión comercial global (2001-2019)
}

\author{
The dynamization of Uruguayan agribusiness chains in the context of global \\ commercial expansion (2001-2019)
}

Ignacio Bartesaghi ${ }^{1}$

(iD) https://orcid.org/0000-0002-3413-3595

Emilio Silva ${ }^{2}$

emsilva@ucu.edu.uy

https://orcid.org/0000-0001-8249-6860

Fecha de recibido: 2 de marzo 2021 Fecha de corrección: 12 de mayo 2021 Fecha de aceptación:1 de julio 2021

\section{Resumen}

La producción y el comercio mundial agroindustrial ha registrado un importante incremento en el presente siglo. Algunos países en América Latina, especialmente los sudamericanos, se han reposicionado como importantes abastecedores de bienes agrarios. Si bien la expansión tiene múltiples causas, el acelerado crecimiento económico que ha evidenciado en los últimos veinte años la región Asia-Pacífico, motorizado principalmente por China, así como otras regiones y países emergentes, ha estado en la base de este proceso. En ese contexto, Uruguay es uno de los países sudamericanos que ha mostrado un importante dinamismo. En este artículo se analiza cómo este país, históricamente agroexportador, acompañó la expansión de la producción y el comercio mundial de base agraria, desarrollando sus vínculos con el mercado externo a partir de sus principales cadenas industriales relacionadas con la producción de soja, forestación, carne, arroz y lácteos. La clave de este proceso implicó, entre otras cosas, una reorganización espacial de las actividades agropecuarias, la captación de inversión extranjera directa, así como potentes transformaciones en materia de innovación tecnológica y gestión de los agronegocios.

Palabras clave: agroindustria, agronegocios, alimentos, comercio mundial, exportaciones, innovación

\section{Abstract}

World agro-industrial production and trade has registered a significant increase in this century. Some Latin American countries, especially in South America, have repositioned themselves as important suppliers of agricultural products. Although the expansion has multiple causes, the accelerated economic growth that the Asia-Pacific region has shown

1 Actualmente es Decano de la Facultad de Ciencias Empresariales de la Universidad Católica del Uruguay y Director del Departamento de Negocios Internacionales e Integración de la misma universidad, Montevideo, Uruguay. Es Postdoctorado en Integración Económica, Doctor en Relaciones Internacionales e integra el Sistema Nacional de Investigadores de la ANII.

2 Se desempeña como Docente e investigador del Departamento de Negocios Internacionales e Integración de la Universidad Católica del Uruguay, Montevideo, Uruguay. El autor es Doctor en Ciencias Sociales y sus principales líneas de investigación se relacionan con comercio, producción y geoeconomía. 
Revista de Política Económica y Desarrollo Sostenible • EISSN: 2215-4167

Vol. 7 (1) • Julio-Diciembre, 2021: 1-34

DOI: https://doi.org/10.15359/peds.7-1.1

Bartesaghi y Silva

URL: http://www.revistas.una.ac.cr/politicaeconomica

in the last twenty years, driven mainly by China, as well as other regions and emerging countries, has been the basis of this process. In this context, Uruguay is one of the South American countries that has shown significant dynamism. This article analyzes how this country, historically agro-exporter, accompanied the expansion of production and world trade based on agriculture, developing its links with the external market from its main industrial chains related to the production of soy, forestry, meat, rice, and dairy products. The key of this process involved, among other things, a special reorganization of agricultural activities, the attraction of foreign direct investment, as well as powerful transformations in terms of technological innovation and agribusiness management.

Keywords: Agroindustry, agribusinesses, foods, world trade, exports, innovation

\section{Introducción}

La producción agraria y el comercio derivado de esta actividad han jugado un papel central en la historia humana. Por esta condición, siempre formaron parte de los intereses geopolíticos y geoeconómicos en todo tiempo y espacio (Picado, 2008). Esta situación se ha visto potenciada en el presente, dado que la población mundial supera los 7.700 millones de personas, y de ella el $54 \%$ ha pasado a vivir en medios urbanos (Umberger, 2015). El acelerado crecimiento económico que ha evidenciado en los últimos veinte años la región de Asia-Pacífico, motorizado principalmente por China, así como otras regiones y países emergentes, ha provocado un reposicionamiento geoeconómico de algunos países agroexportadores, y también, de las principales naciones consumidoras (Perrotti, 2015). En ese sentido, la necesidad de abastecer de comida y de bienes agroindustriales en general a ingentes masas de población, derivada de la elevación de las rentas per cápita y de la urbanización de buena parte del mundo en desarrollo, desataron al inicio del siglo XXI una cuantiosa demanda, que abrió oportunidades sin precedentes en la historia humana para la producción y el comercio de estos productos (Carreño \& Alfonso, 2018).

La magnitud de las trasformaciones recientes es tal que algunos autores en América Latina discuten sobre una posible reversión del deterioro de los términos de intercambio entre países industrializados y aquellos predominantemente agroindustriales, dada la valorización que han cobrado los alimentos a nivel internacional (CEPAL, 2019).

En este contexto, muchos países en desarrollo manifestaron a partir de la década de 2000 profundas transformaciones productivas de base agraria, y un significativo incremento de las exportaciones de productos alimenticios y agroindustriales en general. Este fenómeno se vio favorecido por un aumento de los precios y de la demanda internacional, en el marco de una dinamización de la economía mundial, al influjo, principalmente, de algunos países emergentes (Errea, Peyrú, y Souto, 2011; FAO, 2020).

También incidieron en este proceso la paulatina apertura comercial y la merma del proteccionismo por parte de los países centrales, y también, como sostiene Canta (2014:26) "la creciente interrelación entre los mercados mundiales de los productos básicos y los financieros, debido, entre otros factores, a las bajas tasas de interés y al debilitamiento del dólar registrado durante gran parte del período que se analiza en este artículo”. 
Revista de Política Económica y Desarrollo Sostenible • EISSN: 2215-4167

Vol. 7 (1) • Julio-Diciembre, 2021: 1-34

DOI: https://doi.org/10.15359/peds.7-1.1

Bartesaghi y Silva

URL: http://www.revistas.una.ac.cr/politicaeconomica

La Organización de las Naciones Unidas para la Alimentación y la Agricultura (FAO) indica que, entre los años 2000 y 2018, el comercio agrícola mundial se triplicó en términos de valor y registró una tasa de crecimiento anual de más del $6 \%$, convirtiéndose este período en uno de los más prósperos en transacciones de los últimos cien años (FAO, 2018).

A nivel regional, el Mercosur fue parte importante de este proceso, constituyéndose incluso en un actor clave del crecimiento mundial. En pocos años, el bloque pasó a ser un destacado oferente de productos agroindustriales, superando en algunos rubros a tradicionales a proveedores como Estados Unidos, Canadá, Europa y Oceanía (Consejo Agropecuario del Sur (CAS), 2017). Tanto la producción como las exportaciones de carne y productos agrícolas del Mercosur aumentaron significativamente. Por ejemplo, entre los años 2001 y 2019, la región incrementó su participación en las exportaciones mundiales de carne, pasando del 7\% al 22\%. Particularmente en el caso de las exportaciones de granos oleaginosos, en donde predomina ampliamente la soja, la participación en el comercio internacional pasó del $22 \%$ al $38 \%$ en el mismo período (Internacional Trade Centre, 2019).

En cuanto a los productos forestales, incluyendo la producción y exportación de celulosa, los países suramericanos se han transformado en actores clave. Por ejemplo, con respecto a la celulosa proveniente de madera de no coníferas, los países del Mercosur, sumados a Chile, exportaron en el período 2013-2017 un promedio de 15,6 millones de toneladas, que representó un 61\% del total mundial exportado (Consejo Agropecuario del Sur (CAS), 2017).

En este contexto, en Uruguay las cadenas agropecuarias (en sus fases primaria, industrial y de servicios conexos) han registrado un fuerte dinamismo en términos de producción y productividad. Prueba de ello es el crecimiento que experimentó en la última década el producto interno bruto (PIB) del sector agropecuario en conjunto ( $2 \%$ acumulativo anual), así como el crecimiento que tuvieron la producción agrícola (3\%) y las actividades forestales (9\%) (Ministerio de Vivienda, Ordenamiento Territorial y Medio Ambiente - Universidad de la República (ITU), 2019). Las cadenas de valor agroindustriales se entienden como un complejo de actividades económicas que establecen entre sí relaciones derivadas a partir de una sucesión de operaciones de producción, transformación y comercialización de un producto o grupo de estos en un espacio geográfico concreto; para este caso, coincidente con el territorio uruguayo (Manrique, 2011). En Uruguay las cadenas valor reflejan una condición altamente primarizada y destinada principalmente a las exportaciones del país; por tanto, el análisis a realizar se centrará tanto en la producción primaria como en el proceso de primera industrialización.

En el análisis del tema en cuestión, se parte de la hipótesis de que Uruguay, como país históricamente agroexportador, acompañó la expansión de la producción y el comercio mundial de base agraria, implementando políticas económicas de incentivo a la inversión (particularmente las extranjeras directas) e innovación del sistema agroproductivo, lo cual condujo a reposicionar sus vínculos con el mercado externo a partir de sus principales cadenas industriales relacionadas con la producción de soja, forestación, carne, arroz y lácteos. Algunas de las cadenas se fortalecieron tales son los casos de la carne, el arroz y los lácteos-, y otras directamente se desplegaron durante el 
Revista de Política Económica y Desarrollo Sostenible • EISSN: 2215-4167

Vol. 7 (1) • Julio-Diciembre, 2021: 1-34

DOI: https://doi.org/10.15359/peds.7-1.1

Bartesaghi y Silva

URL: http://www.revistas.una.ac.cr/politicaeconomica

período de referencia, como, por ejemplo, las relacionadas con la soja y la forestación. Este proceso implicó, entre otras cosas, una reorganización espacial de las actividades agropecuarias (Harvey, 2003), la captación de inversión extranjera directa, así como potentes transformaciones en materia de innovación tecnológica y gestión de los agronegocios.

Este artículo se marcó los siguientes objetivos: en primer término, analizar las transformaciones en la producción y el comercio agroindustrial a nivel mundial, para enmarcar dentro de ellas el proceso de Uruguay; y, en segundo lugar, identificar cambios significativos desde el punto de vista productivo, espacial y comercial de las cinco cadenas más importantes de Uruguay, considerando su participación en las exportaciones nacionales.

Este trabajo consta de dos partes. En la primera se presenta una mirada sobre las principales transformaciones agroproductivas, demográficas y comerciales a escala global; en la segunda parte se pondrá el foco en los cambios registrados en las principales cadenas agropecuarias del Uruguay y sus relaciones con el desarrollo de sus exportaciones durante las primeras dos décadas del siglo XXI.

El artículo forma parte de una línea de investigación en curso más amplia, referida al comercio mundial de alimentos y los agronegocios. La estrategia metodológica utilizada articula la revisión de fuentes documentales de origen académico y de organismos internacionales, y el procesamiento y análisis de datos obtenidos de bases estadísticas especializadas en producción y comercio tanto a nivel de Uruguay como mundial.

\section{Desarrollo agroproductivo y comercial en el mundo del siglo XXI}

En esta sección se analizarán los rasgos centrales de los cambios productivos y comerciales a nivel global entre los años 2000 y 2019. Si bien los mismos son parte de un proceso que se extiende más atrás en el tiempo, durante dicho período confluyó una serie de fenómenos, entre otros, económicos, comerciales y demográficos, que provocaron un aumento significativo de la producción y el comercio de bienes agroindustriales. Por razones de acceso a información confiable, los datos se presentarán en ciertos casos a partir de los años 2001 o 2002, y el período, en ocasiones, se cierra en el año 2018.

Se analiza a continuación la evolución de algunos productos de base agraria, tanto primarios como industriales, poniendo atención en aquellos rubros que son importantes en la producción de Uruguay.

Crecimiento mundial de la producción agropecuaria y agroindustrial. A escala mundial la producción agrícola e industrial ha crecido desde el inicio de milenio (FAO, 2020; USDA, 2020). Esto se vio reflejado en todos los productos, superando en la mayoría de los casos la tasa de crecimiento de la población mundial. Este es el caso de los cereales (FAO, 2019). Entre los años 2000 y 2019 la producción de este bien agrario se acrecentó en un 45\%, en tanto que la población mundial creció un $27 \%$ en el mismo período (gráfico 1 ). 
Revista de Política Económica y Desarrollo Sostenible • EISSN: 2215-4167

Vol. 7 (1) • Julio-Diciembre, 2021: 1-34

DOI: https://doi.org/10.15359/peds.7-1.1

Bartesaghi y Silva

URL: http://www.revistas.una.ac.cr/politicaeconomica

Gráfico 1.

Evolución de la población mundial y la producción de cereales. (Periodo 2000-2020)

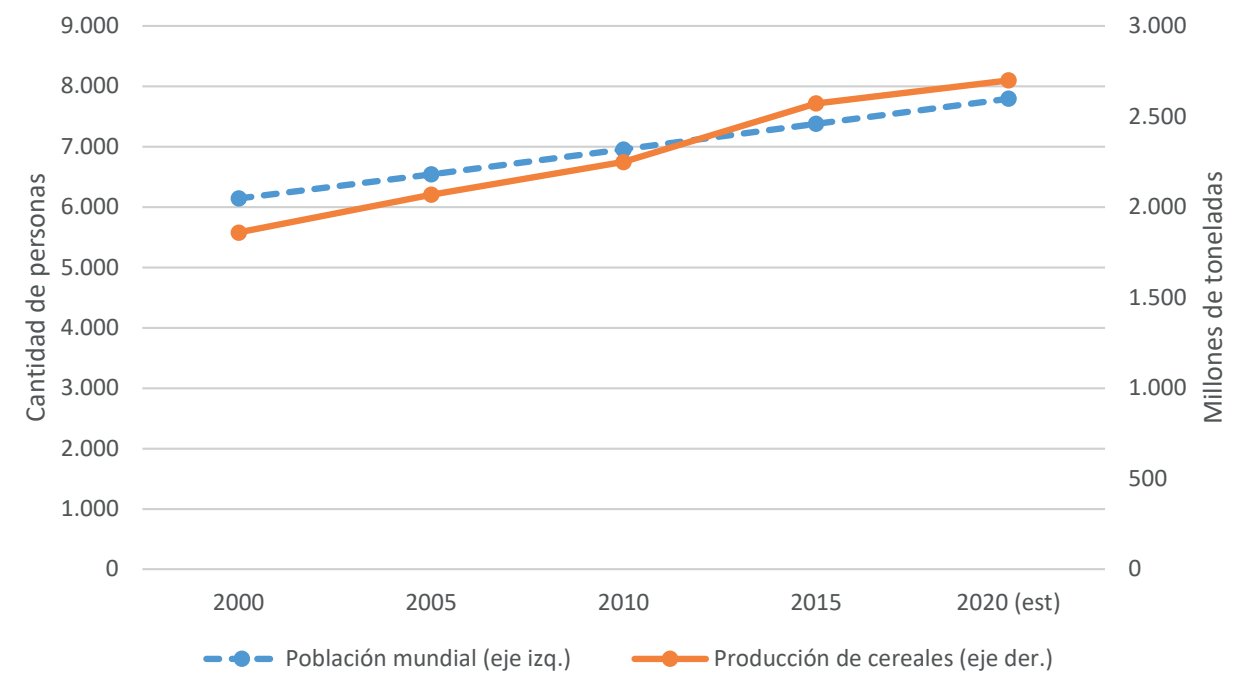

Fuente: Elaboración propia en base a FAO (2019) y Fondo de Población de Naciones Unidas (2020).

Al mismo tiempo, entre los años 2000 y 2019, la producción de habas de soja prácticamente se duplicó (99\%), en tanto la de maíz creció un $81 \%$, la de leche un $34 \%$ y la de arroz un $29 \%$. Por su parte, la producción de carne bovina $(23 \%)^{3}$ y el trigo (24\%) han tenido un crecimiento inferior (USDA, 2020), y son excepciones en relación con todos los demás rubros mencionados, que porcentualmente crecieron por encima de la tasa de población mundial (gráfico 2 y tabla 1).

Tabla 1.

Producción mundial de carne bovina, leche, madera y pulpa de madera. (Años 2000 y 2019, en millones de Ty m³)

\begin{tabular}{lccc}
\hline \multicolumn{1}{c}{ Productos } & 2000 & 2019 & Crecimiento 2000/2019 (en \%) \\
\hline Carne bovina (millones de T) & 47 & 61 & $23 \%$ \\
Trigo (millones de T) & 586 & 753 & $24 \%$ \\
Arroz (millones de T) & 398 & 512 & $29 \%$ \\
Soja (millones de T) & 174 & 342 & $99 \%$ \\
Leche de vaca (millones de T) & 382 & 523 & $34 \%$ \\
Madera $^{4}$ (millones de $\mathrm{m}^{3}$ ) & 3.415 & 3.971 & $16 \%$ \\
Pulpa de madera (millones T) & 169 & 188 & $10 \%$ \\
\hline
\end{tabular}

Fuente: Elaboración propia en base a USDA (2020) y FAOSTAT (2020).

3 Sin perjuicio del incremento porcentual de la producción mundial de carne bovina, en el mismo período se produjo un acelerado crecimiento de las exportaciones de este producto, como se verá más adelante. Es oportuno aclarar que la carne porcina es la que mayor nivel de producción registra, con más de 100 millones de toneladas al año. Sin embargo, en este artículo se analiza la carne bovina por ser uno de los principales productos de exportación de Uruguay.

4 Excepto pulpa de madera. 
Revista de Política Económica y Desarrollo Sostenible • EISSN: 2215-4167

Vol. 7 (1) • Julio-Diciembre, 2021: 1-34

DOI: https://doi.org/10.15359/peds.7-1.1

Bartesaghi y Silva

URL: http://www.revistas.una.ac.cr/politicaeconomica

\section{Gráfico 2.}

Producción mundial de maiz, trigo, arroz y habas de soja (en millones de T). (Periodo 2000/2001-2018/2019

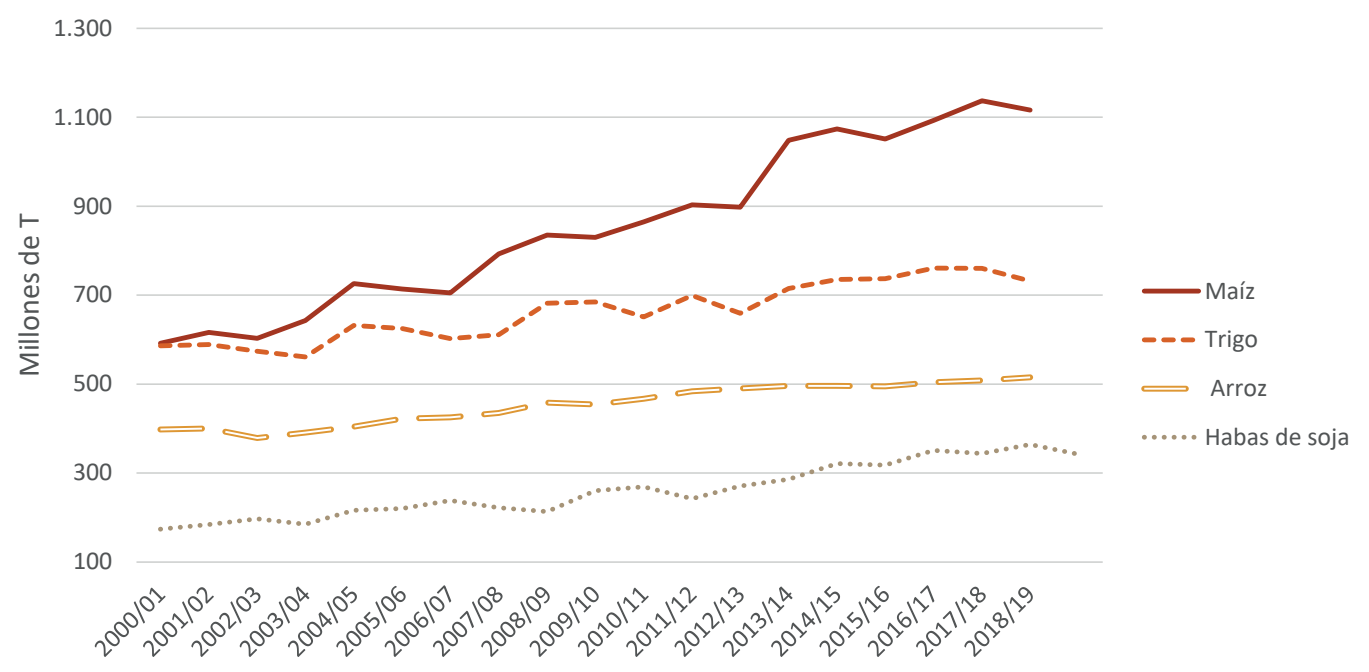

Fuente: Elaboración propia en base a USDA (2020).

Transformaciones recientes en el comercio internacional de productos de base agraria 5 . Entre los años 2001 y 2018, el comercio de estos productos creció a una tasa anual de más del 6\%, pasando de US\$ 357 miles de millones en 2001 a US\$ 1.218 miles de millones en 2018 (gráfico 3; tabla 2). Esta tendencia se ha visto impulsada por la expansión económica mundial (entre los años 2000 y 2018 el PIB se duplicó), el crecimiento demográfico, los avances en el transporte, las tecnologías de la información y la comunicación, y las mejoras generales en el acceso a los mercados (Canta, 2014).

Las habas de soja, el trigo, el vino de uvas frescas y la pasta química de madera, respectivamente, son los productos que han registrado las mayores cifras de exportación, medidas en dólares (Internacional Trade Centre, 2019). Los doce principales productos pasaron a participar del $41 \%$ al $43 \%$ de las exportaciones en el período considerado, y registraron una variación del $256 \%$.

5 Definidos según el criterio del Consejo Agropecuario Sudamericano (CAS). 
Revista de Política Económica y Desarrollo Sostenible • EISSN: 2215-4167

Vol. 7 (1) • Julio-Diciembre, 2021: 1-34

DOI: https://doi.org/10.15359/peds.7-1.1

URL: http://www.revistas.una.ac.cr/politicaeconomica

\section{Gráfico 3.}

Evolución del comercio de productos de base agraria (en miles de millones de US\$). (Periodo 2001-2018)

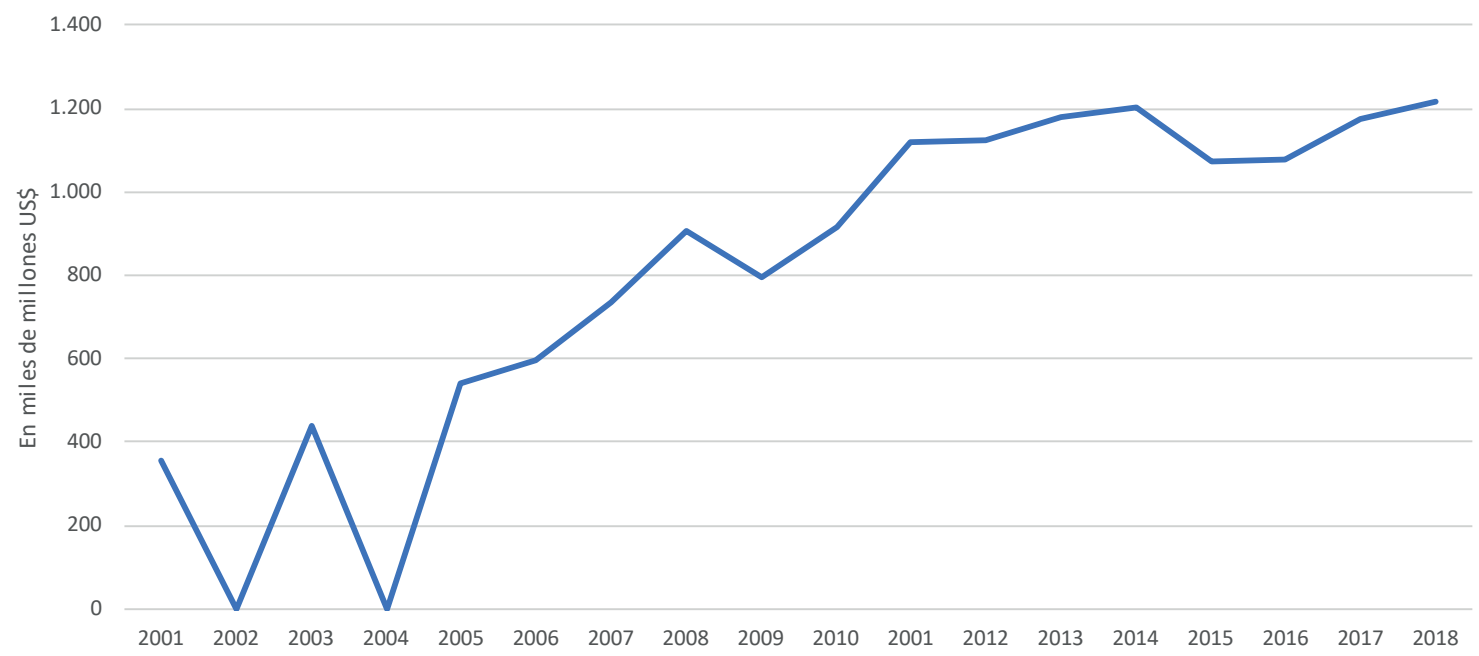

Fuente: Elaboración propia en base a Internacional Trade Centre (2019).

Sin perjuicio de esta desagregación por partidas, si se analiza por capítulos del Sistema Armonizado (SA), en el período considerado, la carne y despojos comestibles (capítulo 02) fue el principal producto exportado. Entre los años 2001 y 2018 pasó de US\$ 41 mil millones a US\$ 128 mil millones, registrando un incremento de la participación del 3\% al 5\% en los alimentos exportados, y con una variación del 474\% (Internacional Trade Centre, 2019). El aceite de palma (partida 1511 del SA), las habas de soja (partida 1201 del SA) y la carne de bovinos congelada (partida 0202 del SA) registraron las mayores variaciones entre los años 2001 y 2018 (635\%, 474\% y 360\%, respectivamente) 
Revista de Política Económica y Desarrollo Sostenible • EISSN: 2215-4167

Vol. 7 (1) • Julio-Diciembre, 2021: 1-34

DOI: https://doi.org/10.15359/peds.7-1.1

Bartesaghi y Silva

URL: http://www.revistas.una.ac.cr/politicaeconomica

Tabla 2.

Exportaciones de productos de base agraria por partidas (periodo 2001-2018)

\begin{tabular}{|c|c|c|c|c|c|}
\hline \multirow{3}{*}{$\begin{array}{c}\text { Partidas } \\
\text { Descripción abreviada }\end{array}$} & \multicolumn{5}{|c|}{ Años 2001-2018 } \\
\hline & \multicolumn{2}{|c|}{ Miles de Millones de US\$ } & \multicolumn{2}{|c|}{ Participación } & \multirow{2}{*}{$\begin{array}{c}\text { Variación } \\
2018 / 2001\end{array}$} \\
\hline & 2001 & 2018 & 2001 & 2018 & \\
\hline 1201. Habas de soja, incluso quebrantadas. & 10,33 & 59,28 & $3 \%$ & $5 \%$ & $474 \%$ \\
\hline 1001. Trigo y morcajo "tranquillón”. & 14,56 & 41,12 & $4 \%$ & $3 \%$ & $182 \%$ \\
\hline 2204. Vino de uvas frescas, incl. encabezado; mosto de uva & 12,91 & 37,51 & $4 \%$ & $3 \%$ & $191 \%$ \\
\hline 4703 Pasta química, de madera, a la sosa “soda” o al sulfato (exc. pasta para disolver). & 13,61 & 37,01 & $4 \%$ & $3 \%$ & $172 \%$ \\
\hline 1005. Maíz & 8,91 & 33,91 & $2 \%$ & $3 \%$ & $281 \%$ \\
\hline 0406 Quesos y requesón & 10,98 & 32,06 & $3 \%$ & $3 \%$ & $192 \%$ \\
\hline 2309. Preparaciones de los tipos utilizados para la alimentación de los animales. & 7,83 & 30,80 & $2 \%$ & $3 \%$ & $293 \%$ \\
\hline 1511. Aceite de palma y sus fracciones, incl. refinados, sin modificar químicamente. & 4,18 & 30,75 & $1 \%$ & $3 \%$ & $635 \%$ \\
\hline 0901. Café, incl. tostado o descafeinado; cáscara y cascarilla de café; sucedáneos de café. & 6,78 & 30,64 & $2 \%$ & $3 \%$ & $352 \%$ \\
\hline 1806. Chocolate y demás preparaciones alimenticias que contengan cacao. & 7,63 & 29,15 & $2 \%$ & $2 \%$ & $282 \%$ \\
\hline 0203. Carne de animales de la especie porcina, fresca, refrigerada o congelada & 11,14 & 28,46 & $3 \%$ & $2 \%$ & $155 \%$ \\
\hline 0207. Carne y despojos comestibles de gallos, gallinas, patos, gansos, pavos. & 9,63 & 26,99 & $3 \%$ & $2 \%$ & $180 \%$ \\
\hline 2304. Tortas y demás residuos sólidos de la extracción del aceite de soja "soya”, incl. Molidos & 7,94 & 26,51 & $2 \%$ & $2 \%$ & $234 \%$ \\
\hline 1006. Arroz & 6,72 & 26,21 & $2 \%$ & $2 \%$ & $290 \%$ \\
\hline 0201. Carne de animales de la especia bovina, fresca o refrigerada. & 7,42 & 24,72 & $2 \%$ & $2 \%$ & $233 \%$ \\
\hline 0202. Carne de bovinos, congelada & 5,32 & 24,48 & $1 \%$ & $2 \%$ & $360 \%$ \\
\hline Subtotal & 145,91 & 519,61 & $41 \%$ & $43 \%$ & $256 \%$ \\
\hline Resto & 211,05 & 698,52 & $59 \%$ & $57 \%$ & $231 \%$ \\
\hline Total & 356,96 & 1218,13 & $100 \%$ & $100 \%$ & $241 \%$ \\
\hline
\end{tabular}

Fuente: Elaboración propia en base a Internacional Trade Centre (2019).

La variación de las exportaciones de los productos de base agraria en el período considerado en este estudio ha evidenciado un crecimiento significativamente superior en relación con el total de productos exportados a nivel mundial (tabla 3). Mientras las exportaciones del total de productos comercializados a nivel mundial registraron, entre los años 2001 y 2018, una variación de 216\%, el porcentaje para los alimentos fue del $241 \%$. Esta realidad pone de manifiesto el significativo rol que ha tomado la producción alimentaria en el contexto del comercio internacional.

Tabla 3.

Variación porcentual comparada entre el total de exportaciones a nivel mundial y los productos de base agraria

\begin{tabular}{rccc}
\hline \multicolumn{1}{c}{ Productos } & \multicolumn{2}{c}{ Miles de millones de US\$ } & Variación \\
& 2001 & 2008 & $2018 / 2001(\%)$ \\
\hline Totales & 6.100 & 19.300 & $216 \%$ \\
Productos de base agria & 357 & 1.218 & $241 \%$ \\
\hline
\end{tabular}

Fuente: Elaboración propia en base a Internacional Trade Centre (2019). 
Revista de Política Económica y Desarrollo Sostenible • EISSN: 2215-4167

Vol. 7 (1) • Julio-Diciembre, 2021: 1-34

DOI: https://doi.org/10.15359/peds.7-1.1

Bartesaghi y Silva

URL: http://www.revistas.una.ac.cr/politicaeconomica

Otra perspectiva de este tema es analizar exclusivamente la exportación de alimentos (capítulos 01 a 23 del SA) por países. En tal sentido, Estados Unidos y los Países Bajos han sido los principales exportadores de alimentos entre los años 2001 y 2018. Al mismo tiempo, en dicho período cobraron vigor como exportadores algunos países emergentes tales como Brasil, India y China. Estos países casi duplicaron su participación en el período de referencia, pasando sus exportaciones agregadas del 8\% al 15\% del total mundial (tabla 4). Esta situación ha implicado que ciertos países emergentes hayan cobrado una mayor importancia geoeconómica en el contexto mundial. El ascenso de algunos de ellos ha sido vertiginoso. Tal es el caso de Brasil, India y Polonia, que han registrado, por ejemplo, un reposicionamiento ascendente en el ranking de naciones productoras y exportadoras de alimentos (Canta, 2014).

En otro orden, tanto Estados Unidos como los Países Bajos y Alemania registraron, al mismo tiempo, un descenso en la participación de las exportaciones, pasando en conjunto del $25 \%$ en el año 2001 al 21\% en el año 2008 (cuadro 3).

Tabla 4.

Principales paises exportadores de productos alimenticios Capitulos 1 al 23 del $S A$

\begin{tabular}{|c|c|c|c|c|c|c|}
\hline \multirow{3}{*}{$\begin{array}{l}\text { Principales países } \\
\text { exportadores de alimentos }\end{array}$} & \multicolumn{6}{|c|}{ Total de exportaciones de productos de capítulos 1 al 23 (SA) } \\
\hline & \multicolumn{2}{|c|}{ Miles de US\$ } & \multicolumn{2}{|c|}{ Participación } & \multirow{2}{*}{$\begin{array}{c}\text { Variación } \\
2018 / 2001\end{array}$} & \multirow{2}{*}{ Incidencia } \\
\hline & 2001 & 2018 & 2001 & 2018 & & \\
\hline Estados Unidos de América & 51.910 .106 & 142.754 .99 & $12 \%$ & $9 \%$ & $175 \%$ & $21 \%$ \\
\hline Países Bajos & 29.549 .425 & 100.685 .449 & $7 \%$ & $7 \%$ & $241 \%$ & $16 \%$ \\
\hline Alemania & 25.143 .093 & 83.067 .407 & $6 \%$ & $5 \%$ & $230 \%$ & $13 \%$ \\
\hline Brasil & 15.320 .406 & 80.597 .457 & $4 \%$ & $5 \%$ & $426 \%$ & $15 \%$ \\
\hline China & 15.062 .446 & 76.139 .880 & $3 \%$ & $5 \%$ & $405 \%$ & $14 \%$ \\
\hline Francia & 31.939 .541 & 72.457 .304 & $7 \%$ & $5 \%$ & $127 \%$ & $9 \%$ \\
\hline España & 17.223.417 & 57.798 .523 & $4 \$$ & $4 \%$ & $236 \%$ & $9 \%$ \\
\hline Canadá & 19.717 .031 & 51.187 .789 & $5 \%$ & $3 \%$ & $160 \%$ & $7 \%$ \\
\hline Italia & 15.882 .447 & 48.187 .287 & $4 \%$ & $3 \%$ & $203 \%$ & $7 \%$ \\
\hline Bélgica & 17.619 .920 & 44.992 .747 & $4 \%$ & $3 \%$ & $155 \%$ & $6 \%$ \\
\hline India & 6.073 .091 & 34.316 .524 & $1 \%$ & $2 \%$ & $465 \%$ & $6 \%$ \\
\hline México & 8.048 .764 & 34.213 .167 & $2 \%$ & $2 \%$ & $325 \%$ & $6 \%$ \\
\hline Argentina & 11.647 .348 & 34.018 .294 & $3 \%$ & $2 \%$ & $192 \%$ & $5 \%$ \\
\hline Indonesia & 4.758 .408 & 33.520 .577 & $1 \%$ & $2 \%$ & $604 \%$ & $7 \%$ \\
\hline Reino Unido & 13.168 .783 & 31.568 .054 & $3 \%$ & $2 \%$ & $140 \%$ & $4 \%$ \\
\hline Australia & 13.198 .067 & 31.350 .885 & $3 \%$ & $2 \%$ & $138 \%$ & $4 \%$ \\
\hline Nueva Zelandia & 6.709 .750 & 24.438 .869 & $2 \%$ & $2 \%$ & $264 \%$ & $4 \%$ \\
\hline Rusia & 1.414 .677 & 24.365 .766 & $0 \%$ & $2 \%$ & $1622 \%$ & $5 \%$ \\
\hline Subtotal & 304.386 .710 & 1.005 .660 .969 & $70 \%$ & $65 \%$ & $230 \%$ & $161 \%$ \\
\hline Resto & 131.616 .855 & 542.913 .409 & $30 \%$ & $35 \%$ & $312 \%$ & $94 \%$ \\
\hline Total & 436.003 .565 & 1.548 .574 .378 & $100 \%$ & $100 \%$ & $255 \%$ & $255 \%$ \\
\hline
\end{tabular}

Fuente: Elaboración propia en base a Internacional Trade Centre, 2019.

Por su parte, si se considera por separado las exportaciones mundiales de carne y despojos alimenticios, de acuerdo con lo que se desprende de la tabla 5, veinte países explican el 90\% de las exportaciones. Estados Unidos ha liderado desde el año 2001 el grupo de países exportadores, en tanto Brasil se posicionó como segundo país exportador, ascendiendo cuatro lugares entre los años 2001 y 2018. 
Revista de Política Económica y Desarrollo Sostenible • EISSN: 2215-4167

Vol. 7 (1) • Julio-Diciembre, 2021: 1-34

DOI: https://doi.org/10.15359/peds.7-1.1

Bartesagbi y Silva

URL: http://www.revistas.una.ac.cr/politicaeconomica

Polonia, India y Argentina han registrado en el mismo período las mayores variaciones positivas en materia de exportaciones de alimentos. Es destacado el caso de India, cuya variación superó $2.300 \%$ en el período 2001-2018. En términos generales, los que han registrado mayores crecimientos son países en desarrollo.

En síntesis, durante los años que han transcurrido del milenio actual, se produjo una importante expansión de la producción y del comercio agrícola. Los países emergentes fueron actores claves en las exportaciones. Entre otros factores, el crecimiento y la urbanización de la población, junto a la mejora del poder adquisitivo en importantes regiones del mundo emergente y a la flexibilización de trabas que obstaculizan el comercio internacional, han motorizado un período de importantes tasas de desarrollo productivo y de los negocios.

Tabla 5.

Evolución de las exportaciones de carnes y despojos comestibles

Principales paises exportadores

\begin{tabular}{|c|c|c|c|c|c|c|}
\hline \multirow{2}{*}{ Exportadores } & \multicolumn{2}{|c|}{ En miles de US\$ } & \multicolumn{2}{|c|}{ Participación } & \multirow{2}{*}{$\begin{array}{l}\text { Variación } \\
\text { 2018/2001 }\end{array}$} & \multirow{2}{*}{$\begin{array}{c}\text { Variación de puestos } \\
\text { en el ranking } \\
(2018-2001)\end{array}$} \\
\hline & $\begin{array}{c}\text { Valor exportado } \\
\text { en } 2001\end{array}$ & $\begin{array}{c}\text { Valor exportado } \\
\text { en } 2018 \\
\end{array}$ & 2001 & 2018 & & \\
\hline Mundo & 40.919 .233 & 128.282 .964 & $100 \%$ & $100 \%$ & 214 & N/A \\
\hline Estados Unidos de América & 6.799 .217 & 17.268 .856 & $17 \%$ & $13 \%$ & $154 \%$ & Sin cambio \\
\hline Brasil & 2.552 .739 & 13.292 .305 & $6 \%$ & $10 \%$ & $421 \%$ & 4 \\
\hline Australia & 3.252 .447 & 10.187 .800 & $8 \%$ & $8 \%$ & $213 \%$ & 1 \\
\hline Países Bajos & 3.569 .712 & 9.494 .037 & $9 \%$ & $7 \%$ & $166 \%$ & -2 \\
\hline Alemania & 2.414 .665 & 8.624 .181 & $6 \%$ & $7 \%$ & $257 \%$ & -3 \\
\hline España & 1.251 .207 & 6.802 .424 & $3 \%$ & $5 \%$ & $444 \%$ & -5 \\
\hline Polonia & 248,432 & 5.994 .065 & $1 \%$ & $5 \%$ & $2313 \%$ & 15 \\
\hline Nueva Zelanda & 1.813 .864 & 5.148 .311 & $4 \%$ & $4 \%$ & $184 \%$ & -2 \\
\hline Canadá & 2.876 .515 & 5.104 .270 & $7 \%$ & $4 \%$ & $77 \%$ & -4 \\
\hline Bélgica & 2.185 .417 & 3.852 .332 & $5 \%$ & $3 \%$ & $76 \%$ & 1 \\
\hline India & 275,002 & 3.726 .988 & $1 \%$ & $3 \%$ & $1255 \%$ & 5 \\
\hline Irlanda & 1.132 .271 & 3.644 .998 & $3 \%$ & $3 \%$ & $225 \%$ & Sin cambio \\
\hline Dinamarca & 3.331 .816 & 3.644 .998 & $8 \%$ & $3 \%$ & $9 \%$ & -10 \\
\hline Francia & 2.499 .371 & 3.547 .397 & $6 \%$ & $3 \%$ & $42 \%$ & -7 \\
\hline Hong Kong, China & 744,673 & 2537,705 & $2 \%$ & $2 \%$ & $241 \%$ & -1 \\
\hline Argentina & 221,601 & 2.530 .983 & $1 \%$ & $2 \%$ & $1042 \%$ & 3 \\
\hline Italia & 861,517 & 2.469 .544 & $2 \%$ & $2 \%$ & $187 \%$ & -4 \\
\hline Reino Unido & 497,597 & 2.179 .285 & $1 \%$ & $2 \%$ & $338 \%$ & -3 \\
\hline México & 214,365 & 1.883 .459 & $1 \%$ & $1 \%$ & $779 \%$ & 1 \\
\hline Uruguay & 258,818 & 1.882 .585 & $1 \%$ & $1 \%$ & $627 \%$ & -3 \\
\hline Subtotal & 37.000 .246 & 113.856 .391 & & & 208 & \\
\hline$\%$ sobre el total mundial & 90 & 89 & $90 \%$ & $89 \%$ & -2 & \\
\hline
\end{tabular}

Fuente: Elaboración propia en base a Internacional Trade Centre (2019). 
Revista de Política Económica y Desarrollo Sostenible • EISSN: 2215-4167

Vol. 7 (1) • Julio-Diciembre, 2021: 1-34

DOI: https://doi.org/10.15359/peds.7-1.1

Bartesaghi y Silva

URL: http://www.revistas.una.ac.cr/politicaeconomica

\section{Transformaciones productivas y agroexportadoras en Uruguay}

En esta parte abordaremos el desarrollo de las cinco cadenas agroindustriales más importantes con que cuenta el país: soja, forestación, arroz, carne y leche. En primer lugar, se hará referencia al desarrollo productivo que han registrado estas cadenas en las últimas dos décadas, para luego centrarse en el comercio internacional de los productos que se derivan de las mismas.

El inicio de la década de 2000 constituyó un punto de inflexión en el sistema productivo de Uruguay. En todo el territorio, pero con especial énfasis en las adyacencias del río Uruguay, se produjeron importantes transformaciones motorizadas principalmente por la demanda internacional, las condiciones naturales y políticas del país, y la afluencia de nuevas inversiones de capitales extranjeros. Se potenciaron algunos rubros tradicionales como la producción de carne, lácteos y arroz; al mismo tiempo que se instalaron nuevas actividades agroindustriales como la producción de pasta de celulosa y la producción de soja, que hasta ese momento tenía escasa relevancia en el país. Este cultivo se fue expandiendo en la década de 2000, desde el territorio argentino hacia el uruguayo (en particular hacia algunos departamentos fronterizos con Argentina del litoral del Río Uruguay), generando importantes transformaciones en el medio rural, en las estructuras agrarias, en los modos de propiedad de la tierra y en la forma de producir valor (Achkar, Domínguez \& Pesce, 2006). Las inversiones fueron ejecutadas por empresas argentinas, muchas veces con financiamiento de su propio país, pero también canalizando IED transnacional.

Los principales rubros tradicionales de Uruguay (maíz, girasol, trigo, cebada, lino, avena, sorgo) fueron perdiendo importancia relativa. En el plano industrial, se instaló en Fray Bentos a mediados de la década de 2000 la empresa de capitales finlandeses Botnia (hoy UPM), abocada a la producción de pasta de celulosa. Surgía así una nueva agroindustria, en este caso vinculada a la forestación.

Esta industria es parte de un proceso de desarrollo de la actividad forestal que fue impulsado al final de los años 80 por una serie de políticas de Estado que estimularon esta actividad. La más importante se implementó a través de la Ley Forestal № 15.939 del año 1987. Al mismo tiempo, hacia el centro y norte del Uruguay (departamentos de Artigas, Salto, Paysandú) se expandió la frontera arrocera del sur de Brasil (Achkar, Domínguez \& Pesce, 2008).

Continuando también con una política de desarrollo lechero originada en la década de 1980, este sector se ha constituido en un rubro importante para Uruguay en materia de producción y comercio, más allá de fluctuaciones coyunturales.

Los cambios productivos mencionados tienen que ver con un modelo de agricultura industrial que ha transformado el medio rural a gran velocidad en las tres últimas décadas, y que son derivaciones de la llamada "revolución verde". La misma se ha caracterizado por la creciente incorporación de insumos (herbicidas, insecticidas, fungicidas, fertilizantes químicos) y maquinarias a los sistemas productivos (Blum, Narbondo \& Oyhantcabal, 2008). Este fenómeno se asocia con la idea de "industrialización de la agricultura”, en la cual los agricultores dejan de realizar determinadas tareas tradicionales, que pasan a ser sustituidas por los insumos proporcionados por grandes empresas especializadas en el tema 
Revista de Política Económica y Desarrollo Sostenible • EISSN: 2215-4167

Vol. 7 (1) • Julio-Diciembre, 2021: 1-34

DOI: https://doi.org/10.15359/peds.7-1.1

Bartesaghi y Silva

URL: http://www.revistas.una.ac.cr/politicaeconomica

(Otero \& Lario, 1999). Se sostiene en un modelo productivo dinámico, integrado y holístico que se asocia a un nuevo tipo de gestión empresarial centrada en los agronegocios.

El término 'agronegocios' ('agribusinesses', en inglés) se define por la totalidad de las actividades económicas tales como la compra de insumos, la producción y la distribución de productos agropecuarios. Tiene que ver con la articulación y la creciente relación de la actividad agrícola con la cadena productiva antes y después de producir. Esta cadena incluye, entre otros eslabones, a la industria y el comercio que proporcionan insumos, al transporte, al procesamiento y venta de los productos agropecuarios hasta el consumidor final. La producción agraria implica siembra, manejo, cosecha, rendimientos, mantención de máquinas, almacenamiento de insumos, descarte de embalajes y personal. En forma previa, el productor rural necesita adquirir una serie de elementos para producir: máquinas, agentes químicos, fertilizantes, semillas, entre otros insumos. Posterior a la producción, el eslabonamiento continúa con el almacenamiento y la distribución, incluida la logística hasta llegar al consumo (Ribeiro y Fornazier, 2016, pág. 219).

En este escenario de concentración es que aparecieron grandes corporaciones económicas, que se ubicaron en aquellos sectores de la cadena agroindustrial más dinámicos y que influyeron decisivamente en los procesos productivos. Así, se concentró en muy pocas firmas buena parte de la oferta de semillas, fertilizantes, agroquímicos, maquinaria, entre otros insumos. También participan en la industrialización y comercialización de lo producido (Blum, Narbondo, \& Oyhantcabal, 2008).

Implicancias de la política económica en las cadenas agroindustriales en Uruguay. Es importante destacar que el desarrollo de las cadenas productivas no fue fruto exclusivamente de una demanda internacional creciente. Sin perjuicio de ello, el país implementó una serie de medidas que alentaron al sistema productivo a acompañar dicho proceso. Para comprender mejor este aspecto, es necesario hacer mención a los rasgos principales de las políticas económicas implementadas en el período considerado.

A diferencia de lo ocurrido en buena parte de América Latina en la última década del siglo XX, el Estado uruguayo no se retiró significativamente de su capacidad de influir en los aspectos tanto económicos como sociales. El objetivo principal a nivel macroeconómico fue el abatimiento de la inflación, para lo cual se adoptaron diversas medidas en las áreas fiscal y cambiaria.

Al inicio del nuevo siglo, Uruguay enfrentó una profunda crisis económica que también afectó a todos los miembros del Mercosur entre los años 2001 y 2003. A partir de ese año se registró un importante proceso de recuperación traccionado por el incremento de la demanda de alimentos desde los países emergentes, que dio paso a uno de los mayores períodos de crecimiento económico de la región. Este período de bonanza se asoció no solo con una coyuntura internacional favorable sino también con la aplicación de un modelo económico centrado en políticas de desarrollo productivo (Bértola, 2018a).

A partir del primer lustro de los años 2000, desde la política económica del país se implementaron más de 180 de instrumentos de apoyo al desarrollo productivo, entre otros referidos a subsidios, instrumentos financieros, programas de asistencia y servicios técnicos pagos (Torres, 2019). 
Revista de Política Económica y Desarrollo Sostenible • EISSN: 2215-4167

Vol. 7 (1) • Julio-Diciembre, 2021: 1-34

DOI: https://doi.org/10.15359/peds.7-1.1

Bartesaghi y Silva

URL: http://www.revistas.una.ac.cr/politicaeconomica

No obstante, en términos de impactos, y sumados obviamente a otras dimensiones de la política económica en su conjunto, se destacan dos instrumentos: el régimen de zonas francas (ZF) y la Ley de Inversiones, que contribuyeron notoriamente a la captación de inversión extranjera directa (IED), destinada principalmente al sector agroproductivo.

La premisa que rigió la política post crisis económica partió de que Uruguay tiene un mercado interno reducido que le acota los márgenes de autonomía con relación a la dinámica económica internacional, y por tanto el potencial de crecimiento económico debía focalizarse en sus exportaciones. En ese sentido, se determinó un conjunto de sectores productivos con potencial exportador con impacto sobre el empleo. El fomento de las exportaciones de bienes (especialmente agroindustriales) y servicios fue una política claramente delineada en los planes de gobierno, al mismo tiempo que el diseño de instrumentos para atraer la IED y maximizar su aporte al desarrollo. La idea principal fue mantener las condiciones que posibilitaron un salto en la inversión recibida desde el 2004. Es decir, continuar con un clima de negocios atractivo, donde el Estado, a su vez, debía proveer bienes y recursos que facilitaran la inserción comercial (Oficina de Planeamiento y PresupuestoPresidencia de la República, 2009).

Estas políticas tuvieron como finalidad desarrollar sectores específicos de la economía, alentando en muchos casos actividades productivas nuevas, consideradas estratégicas y no basadas exclusivamente en las ventajas comparativas tradicionales del país, mediante diferentes instrumentos de política: comerciales, tecnológicos, tributarios, financieros, institucionales y normativos.

Tanto el régimen de ZF como la Ley de Inversiones han sido esenciales para el despegue de las cadenas productivas aquí analizadas (Bértola, 2018b). En tal sentido, el régimen de ZF logró captar inversiones que superaron entre 2005 y 2014 los 5.700 millones de dólares. La clave del régimen es, entre otros beneficios, la exoneración de todo tributo nacional (creado o por crearse), lo que estimuló la instalación de más de 1.300 empresas que se ampararon al mismo. A modo de ejemplo, esto implicó que el más del 90\% de las exportaciones de soja y madera se realizara a través de zonas francas en el período considerado en este artículo.

Por su lado, la Ley de Inversiones estableció beneficios para las actividades productivas como la exoneración de impuestos para bienes muebles destinados directamente al ciclo productivo. Este nuevo escenario de promoción de inversiones ha sido muy utilizado por las empresas extranjeras que se instalaron en Uruguay, y que no hicieron uso del régimen de ZF. Durante el período 2009-2016, el 43 \% del monto de inversiones aprobadas tuvo relación con emprendimientos de empresas extranjeras (Torres, 2019).

Cambios productivos y espaciales en la geografía económica de Uruguay. El sector agrícola del país se desarrolló inicialmente con el objetivo de satisfacer las demandas del mercado interno, alcanzando una superficie máxima de ocupación del suelo a principios de 1950 de casi un millón de hectáreas. Progresivamente, y como consecuencia del abandono del modelo de sustitución de importaciones, la actividad agrícola comenzó a reducir las áreas cultivadas y el número de agricultores, presentando un proceso continuo de tecnificación, aumento y concentración de la producción (De los Campos \& Pereira, 2019). En 1990 se alcanzó a un promedio de 470 mil hectáreas ocupadas por el sector, con seis productos 
Revista de Política Económica y Desarrollo Sostenible • EISSN: 2215-4167

Vol. 7 (1) • Julio-Diciembre, 2021: 1-34

DOI: https://doi.org/10.15359/peds.7-1.1

Bartesagbi y Silva

URL: http://www.revistas.una.ac.cr/politicaeconomica

principales: arroz, trigo, cebada, girasol, maíz y sorgo. Estos cultivos generaban cerca del $50 \%$ del producto bruto del sector agropecuario (Arbeletche \& Carballo, 2006a). No obstante, en 1990 se comenzó a dar una mayor vinculación del sector agroindustrial con el mercado externo, que pasó a constituir el 37\% de los ingresos del sector ${ }^{6}$ (Instituto Interamericano de Cooperación para la Agricultura, 2007). Esto indicó un punto de inflexión, que se consolidó a inicios del siglo XX, en la orientación de la producción del sector agropecuario hacia el mercado internacional.

Transformaciones espaciales. Entre los años 1990 y 2011, se registraron los mayores cambios a nivel de la distribución espacial y producción de las actividades agropecuarias en el territorio de Uruguay (mapa 1 A y B). Si se considera el período 2000-2019, las tierras dedicadas a la agricultura pasaron del 14\% al 25\%, las forestales del 5,9\% al 6,5\%; en tanto la superficie agrícola-ganadera creció un $25 \%$, al tiempo que tendió a densificarse hacia el centro y este del país, debido al avance de la frontera sojera por el litoral del país (Ministerio de Ganadería, Agricultura y Pesca, 2019).

Mapa 1 (A y B).

Transformaciones espaciales de los principales rubros agropecuarios (1990-2011)

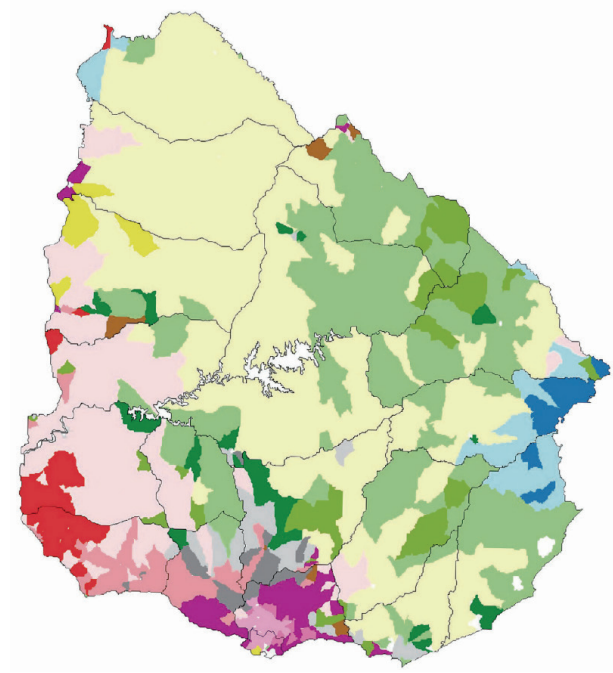

Mapa 1.A. Año 1990

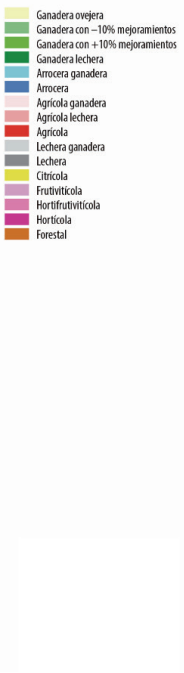

Mapa 1.B. Año 2011

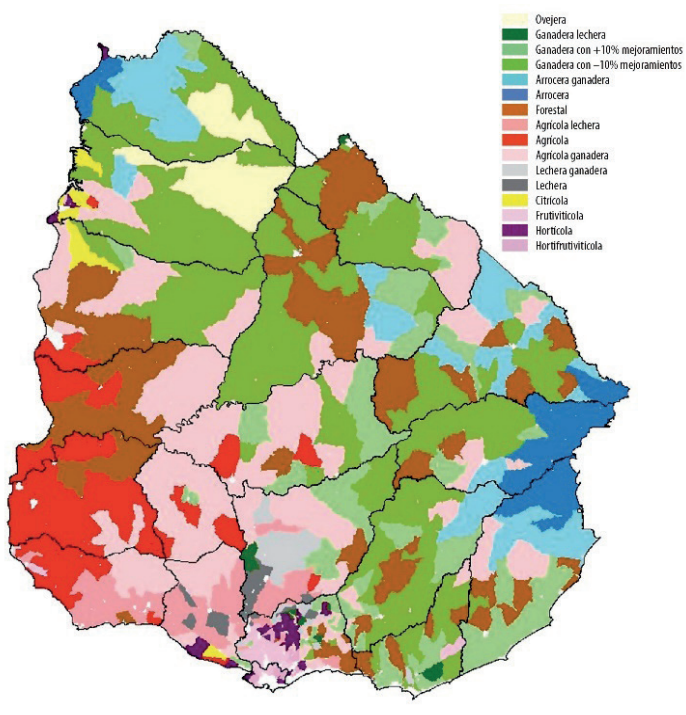

Fuente: Ministerio de Ganadería, Agricultura y Pesca (2019).

La producción sojera en los departamentos de Paysandú, Río Negro, Soriano, Colonia, Flores y

6 En 1960 representaba un 4\% de los ingresos del sector agroindustrial (IICA, 2007). 
Revista de Política Económica y Desarrollo Sostenible • EISSN: 2215-4167

Vol. 7 (1) • Julio-Diciembre, 2021: 1-34

DOI: https://doi.org/10.15359/peds.7-1.1

Bartesaghi y Silva

URL: http://www.revistas.una.ac.cr/politicaeconomica

Durazno, y el cultivo de arroz en Salto y Artigas, se convirtieron en los rubros agrícolas más importantes en las regiones litoral del Rio Uruguay y centro del país. La forestación ha tenido su mayor desarrollo en los departamentos Río Negro, Paysandú, Rivera, Tacuarembó y Cerro Largo, principalmente; en tanto se intensificó la producción arrocera en el este del país. Por su parte, la actividad ganadera fue ocupando suelos menos propicios para la agricultura, desplazándose paulatinamente desde el litoral oeste hacia otras regiones del país (mapa 2).

Mapa 2.

Porcentaje de explotaciones con bovinos de carne como principal ingreso (Censos 2000 y 2011)
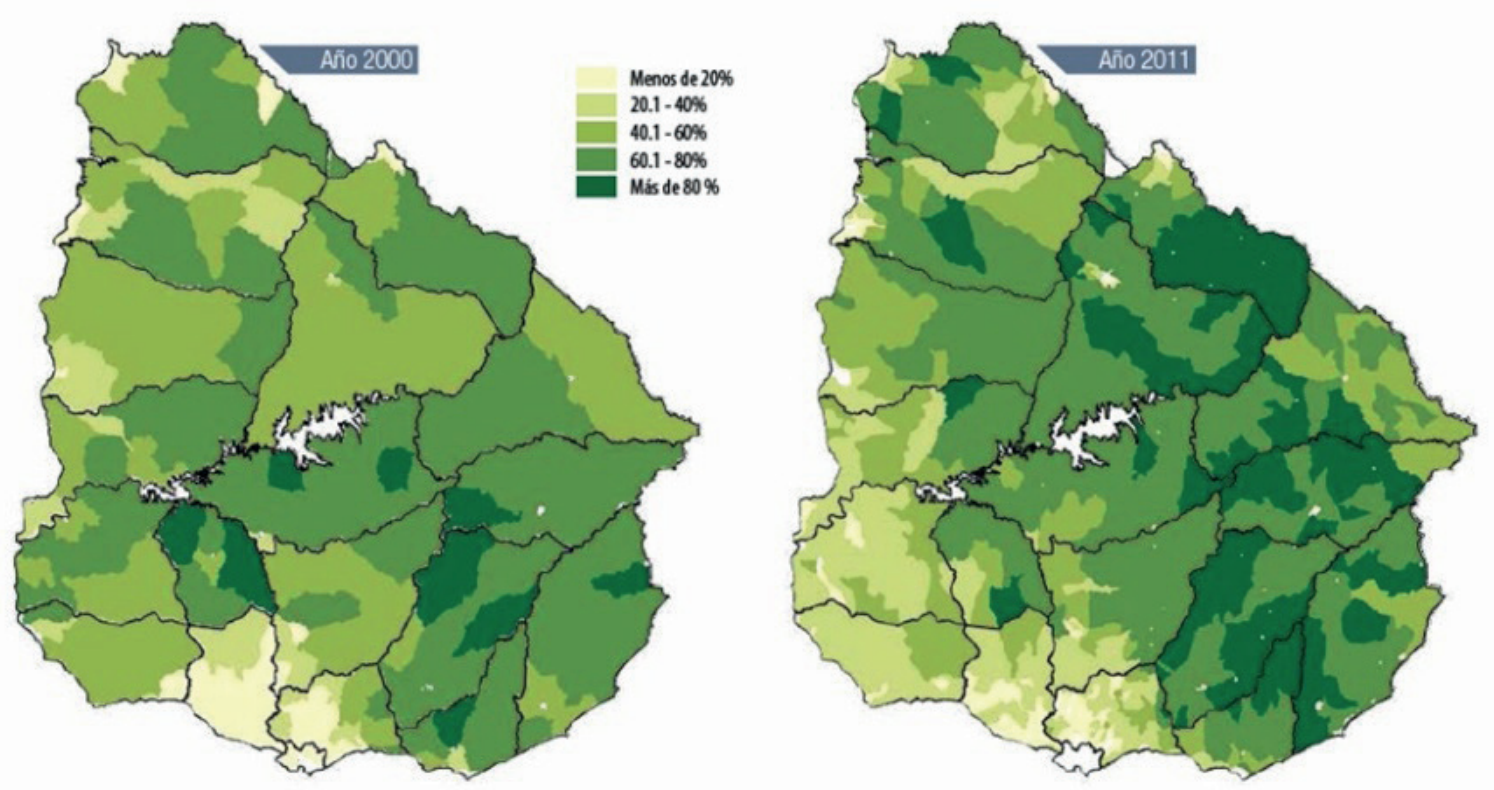

Fuente: Reproducido de Ministerio de Ganadería, Agricultura y Pesca (2014).

Cambios productivos. A continuación, se analizarán las principales cadenas productivas atendiendo algunas dimensiones claves como la evolución de la producción en toneladas, la expansión de la superficie ocupada con el paso del tiempo y aspectos logísticos básicos que tuvieron que desarrollarse para darle sostenibilidad al proceso de crecimiento.

Cadena sojera. A principios del siglo XXI, la irrupción del cultivo de soja como expansión de la producción agrícola argentina que buscó en Uruguay mejores condiciones económicas y políticas convirtió a este producto en el principal rubro de la agricultura uruguaya, desplazando a la producción de arroz ${ }^{7}$

7 Si bien el arroz dejó de ser el principal producto agrícola de exportación de Uruguay, a la vez comenzó a tener mayor preponderancia en el litoral oeste y noroeste del país. Este cultivo era, inicialmente, tradicional en los departamentos del este del país (Achkar, 2006). 
Revista de Política Económica y Desarrollo Sostenible • EISSN: 2215-4167

Vol. 7 (1) • Julio-Diciembre, 2021: 1-34

DOI: https://doi.org/10.15359/peds.7-1.1

Bartesaghi y Silva

URL: http://www.revistas.una.ac.cr/politicaeconomica

que, durante muchos años, constituyó el principal generador de excedentes exportables del sector agrícola uruguayo. A partir del año 2000 se produjo un incremento acelerado de la superficie destinada a la plantación de soja. Entre las zafras de los años 2000/01 y 2018/2019 se pasó de 157 mil hectáreas a 960 mil, llegando a un máximo de 1.334.000 hectáreas en la zafra de los años 2014/15. Entre tanto, la producción pasó de 1 millón de toneladas a 2,8 millones entre 2000/01 y 2018/2019, con un pico de 3,2 millones de toneladas en la zafra 2016/17 (Ministerio de Ganadería, Agricultura y Pesca, 2019).

La cadena de soja representa un $17 \%$ de la producción (medida en toneladas) que se analiza en este artículo. Su materia prima es el grano producido bajo la modalidad de agricultura de secano (Ministerio de Vivienda, Ordenamiento Territorial y Medio Ambiente - Universidad de la República (ITU), 2019).

A partir de la zafra 2003/2004, es el cultivo que ocupa mayor extensión territorial. Al mismo tiempo, el espacio que ocupaban los cultivos tradicionales en el período anterior (girasol, lino, maíz, trigo, entre otros) disminuyó sensiblemente (Dirección Nacional de Medio Ambiente, 2014).

El desarrollo de la soja en Uruguay fue favorecido, entre otros factores, por el incremento de la demanda internacional (especialmente china) y el alza de los precios internacionales, las condiciones impositivas más ventajosas y los bajos costos de producción en Uruguay en comparación inicialmente con Argentina (Guibert et al., 2011), la introducción de un avanzado paquete tecnológico, la estabilidad política, la promoción y el establecimiento de condiciones favorables para las inversiones extranjeras directas (IED), el alza de los precios de la tierra como incentivo al uso intensivo y la adecuada dotación de recursos naturales.

Desde el punto de vista de la gestión, incursionar en la soja y desarrollarla requirió importantes transformaciones en todas las fases. Tanto los antiguos actores (sobre todo nacionales) como los nuevos (predominantemente argentinos) se alinearon en algunas ideas básicas de agronegocios tales como la rotación de capital y su desplazamiento de fijo a variable, el uso de tecnología de punta para este tipo de producción, arrendamiento en lugar de adquisiciones de tierras, tercerización de los servicios (siembra, fumigación, cosecha) (Gutiérrez, 2009).

Los mayores volúmenes de producción tendieron a presionar la infraestructura logística existente, especialmente la destinada al almacenamiento y al transporte. En tal sentido, la capacidad de almacenaje pasó de 2,5 millones de toneladas a de 6,8 millones en el período de referencia (Ministerio de Ganadería, Agricultura y Pesca, 2019).

De manera congruente con la espacialidad de la soja, la mayor densidad de almacenaje y flujos de carga está concentrada en el litoral del río Uruguay y centro del país (gráfico 4). Los puertos más importantes de salida de las exportaciones son Nueva Palmira (más de 2,6 millones de toneladas) y Montevideo (0,7 millones de toneladas).

Prácticamente toda la soja se comercializa en granos y su principal cliente es China; la industrialización de este producto es marginal, y esto constituye una carencia de la cadena. Por esta razón Uruguay es importador de pellets y aceite de soja. Mientras que Uruguay industrializa el $5 \%$ de su producción elaborando harinas de soja y aceites, Argentina lo hace en un 90\% (Ciani, Reus, \& Aramayo, 2018). 
Revista de Política Económica y Desarrollo Sostenible • EISSN: 2215-4167

Vol. 7 (1) • Julio-Diciembre, 2021: 1-34

DOI: https://doi.org/10.15359/peds.7-1.1

Bartesaghi y Silva

URL: http://www.revistas.una.ac.cr/politicaeconomica

Gráfico 4.

Capacidad y dinámica logistica relacionada con la soja

SOM: Logística

MAPA GENERAL, 2011-2014

EFERENCIAS

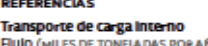

Poblacion
CEISO INE 2011

- 1

1
$-\quad 10$
50

50
$-\quad 100$

1

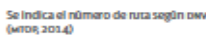

Exportaciones
Plujo

$\Rightarrow \quad$ Prowto de sauom

(MILES DE TON. POEAMO)

Almacenamiento

Capaddad de acoplo (Muess DE TON)

- 5,0

- 10,0

ㄴ. 50,0

․ㅡ 100,0

territorios de agroexportación
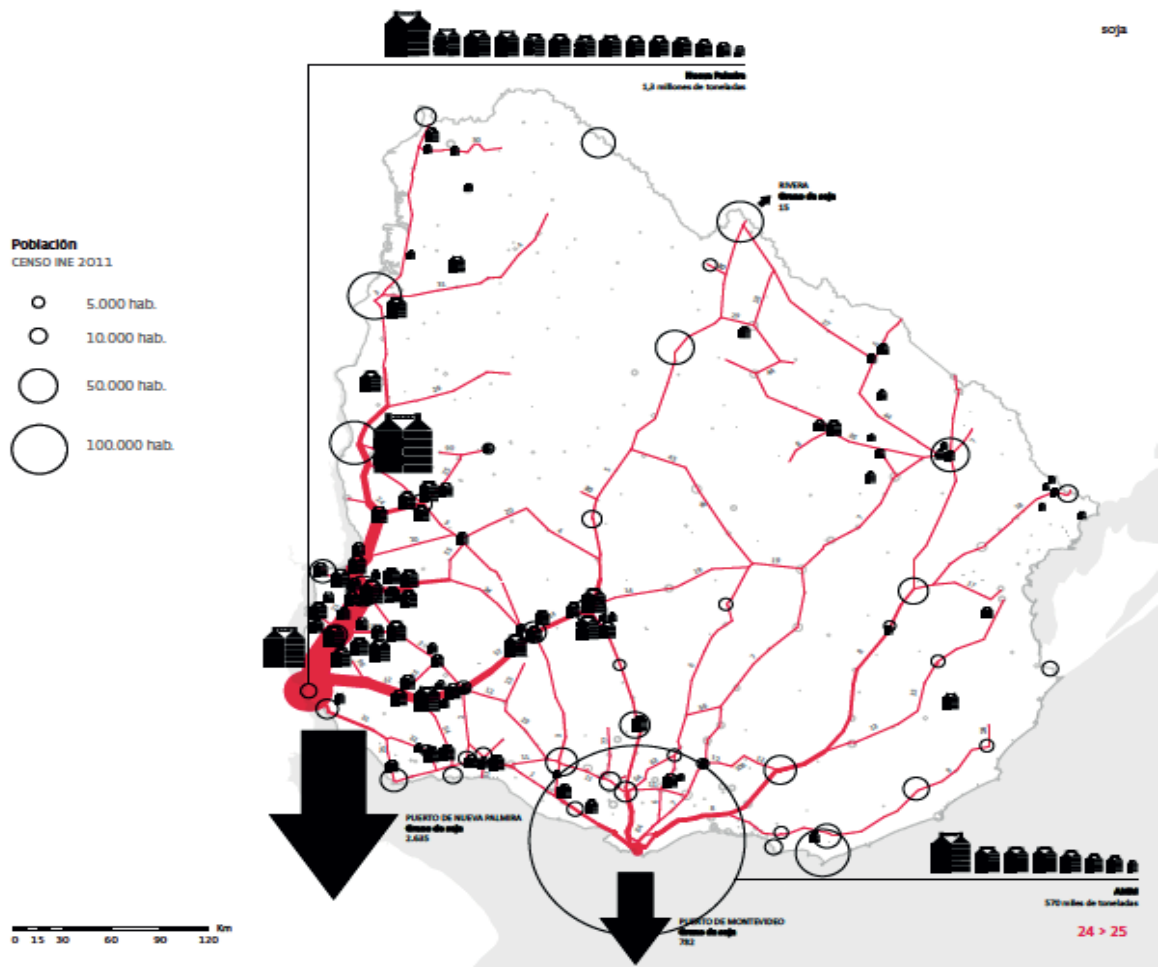

Fuente: Reproducido de Ministerio de Vivienda, Ordenamiento Territorial y Medio Ambiente - Universidad de la República (ITU), (2019:25).

Cadena cárnica vacuna. Por su historia e importancia en la matriz productiva nacional, esta cadena tiene gran relevancia económica y social. Considerando las fases primaria e industrial, actualmente representa el $7 \%$ de las toneladas producidas por las cinco principales cadenas agroindustriales del país.

Esta actividad ha demostrado en todas sus fases, también, un significativo desarrollo entre inicios en el período de análisis, con un comportamiento ascendente en indicadores tales como producción, exportación, inversión e innovación. Esto se ha registrado en un contexto de reducción de superficie destinada exclusivamente a la ganadería, lo que habla de un incremento de la productividad si se consideran los resultados de las últimas dos décadas (Aguirre, 2020). Entre los años 2002 y 2018 el stock bovino pasó de 11,2 millones de cabezas a 11,4 millones (gráfico 5). Las faenas pasaron de 1,4 millones de cabezas en el año 2001 a 2,5 millones en el año 2018, que representaron 1.100 millones de toneladas de carne vacuna (Ministerio de Ganadería, Agricultura y Pesca-DIEA, 2019). 
Revista de Política Económica y Desarrollo Sostenible • EISSN: 2215-4167

Vol. 7 (1) • Julio-Diciembre, 2021: 1-34

DOI: https://doi.org/10.15359/peds.7-1.1

Bartesagbi y Silva

URL: http://www.revistas.una.ac.cr/politicaeconomica

Alrededor del 6,8\% se destina al mercado interno. El 98\% del ganado se destina a la industria, en tanto un $2 \%$ se exporta en pie (Instituto Nacional de Carnes-INAC, 2018).

El desarrollo de la fase industrial ha estado asociado a las inversiones de capitales extranjeros destinados a la compra de emprendimientos establecidos y el desarrollo de nuevas plantas. Los frigoríficos están distribuidos por todo el país, pero la mayor concentración se registra en el área metropolitana de Montevideo (Ministerio de Vivienda, Ordenamiento Territorial y Medio Ambiente - Universidad de la República (ITU), 2019).

\section{Gráfico 5.}

Evolución de las cabezas de bovinos (en miles)

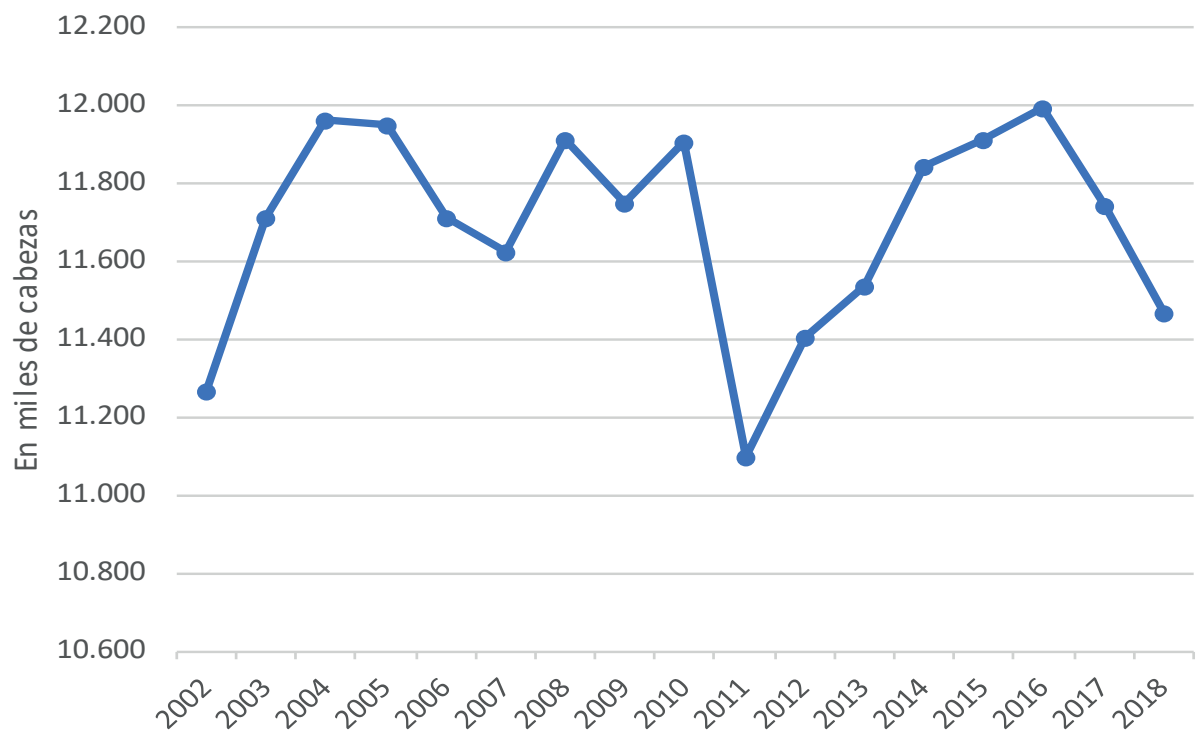

Fuente: Elaboración propia en base a Ministerio de Ganadería, Agricultura y Pesca (2019).

En materia de empleo, la cadena ocupa directamente a más de 63.000 personas. En la fase primaria trabaja el 79\% de los ocupados en el sector (gráfico 6). 
Revista de Política Económica y Desarrollo Sostenible • EISSN: 2215-4167

Vol. 7 (1) • Julio-Diciembre, 2021: 1-34

DOI: https://doi.org/10.15359/peds.7-1.1

Bartesaghi y Silva

URL: http://www.revistas.una.ac.cr/politicaeconomica

Gráfico 6.

Fases de la cadena cárnica vacuna

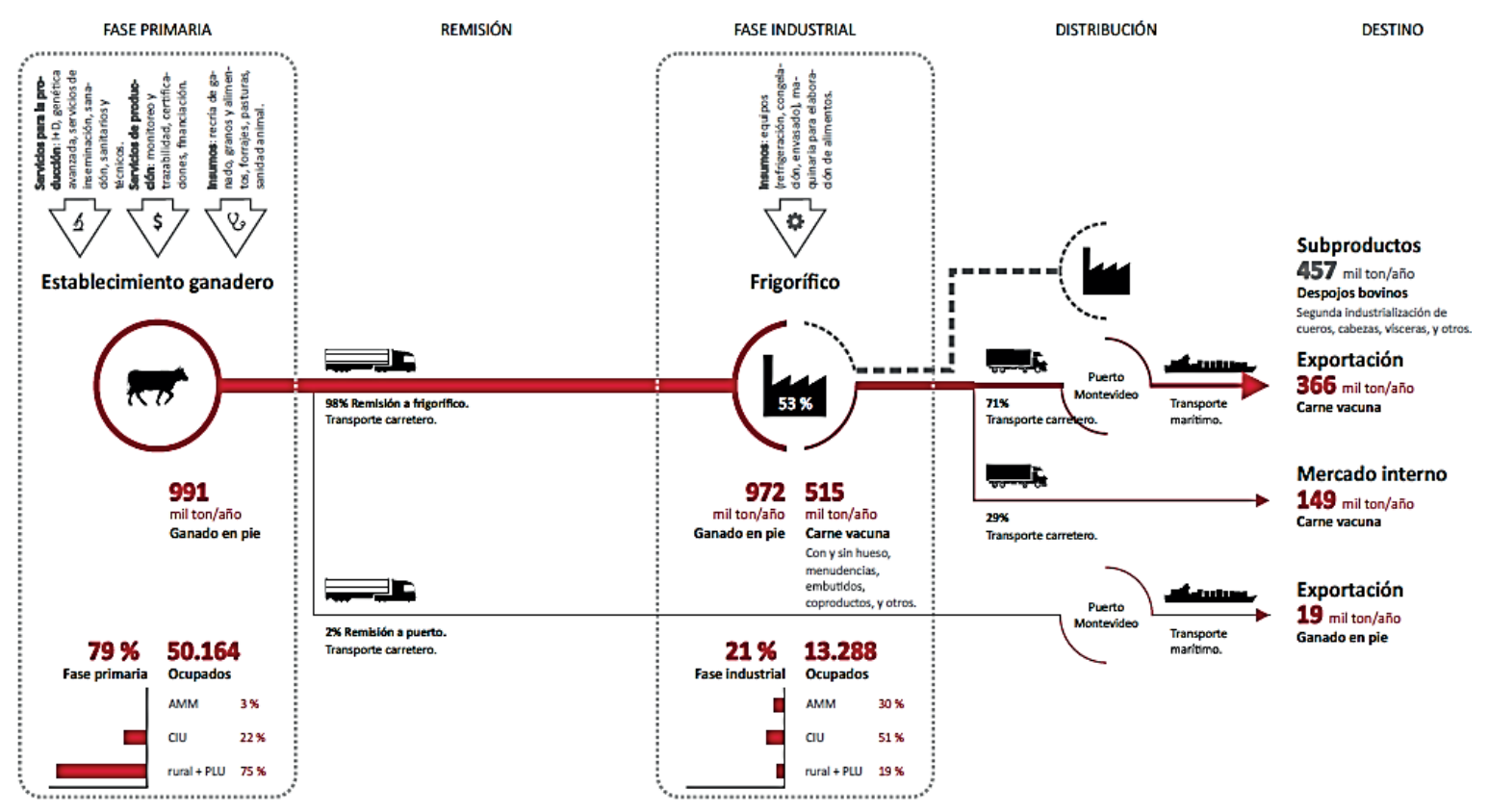

Fuente: Reproducido de Ministerio de Vivienda, Ordenamiento Territorial y Medio Ambiente - Universidad de la República (ITU), (2019:86).

El transporte hacia los frigoríficos se realiza en camiones de mediano porte, a través de la mayor parte de la red vial primaria y secundaria del Uruguay. No obstante, las rutas $\mathrm{N}^{\circ} 3,5$ y 8 son las que registran los mayores flujos de transporte. A su vez, el traslado desde los frigoríficos hasta el puerto de Montevideo (principal punto de salida) o hacia los centros de consumo interno se realiza en camiones de 25 toneladas.

Cadena forestal. El año 1987 marcó un punto de inflexión para las actividades forestales del Uruguay. La Ley Forestal 15.939, aprobada ese año, estableció una serie de incentivos que impulsó un cambio estructural en este sector productivo. De ahí en más, tanto la superficie forestada como el volumen de madera extraída y su industrialización tuvieron un desarrollo importante, lo cual contribuyó con los cambios de la matriz productiva del país registrada en las últimas décadas (Ministerio de Ganadería, Agricultura y Pesca-DIEA, 2019).

Actualmente el sector forestal uruguayo tiene capacidad industrial para procesar 10,4 millones de m3 de madera, de los cuales el 88\% (9,2 millones de m3) se consume para la obtención de pasta de celulosa, y el $12 \%$ restante (1,2 millones de $\mathrm{m} 3)$ es procesado por el sector aserrado. En los últimos 20 
Revista de Política Económica y Desarrollo Sostenible • EISSN: 2215-4167

Vol. 7 (1) • Julio-Diciembre, 2021: 1-34

DOI: https://doi.org/10.15359/peds.7-1.1

Bartesagbi y Silva

URL: http://www.revistas.una.ac.cr/politicaeconomica

años la superficie forestada creció un $85 \%$ (gráfico 7), y se multiplicó por más de 30 si se considera que a finales de la década de 1980 apenas había algo más de 30 mil hectáreas plantadas. Por su parte, la extracción de madera creció alrededor del 500\% desde el inicio del año 2000 al presente (gráfico 8).

\section{Gráfico 7.}

Superficie plantada (en ha). Periodo 2000-2018

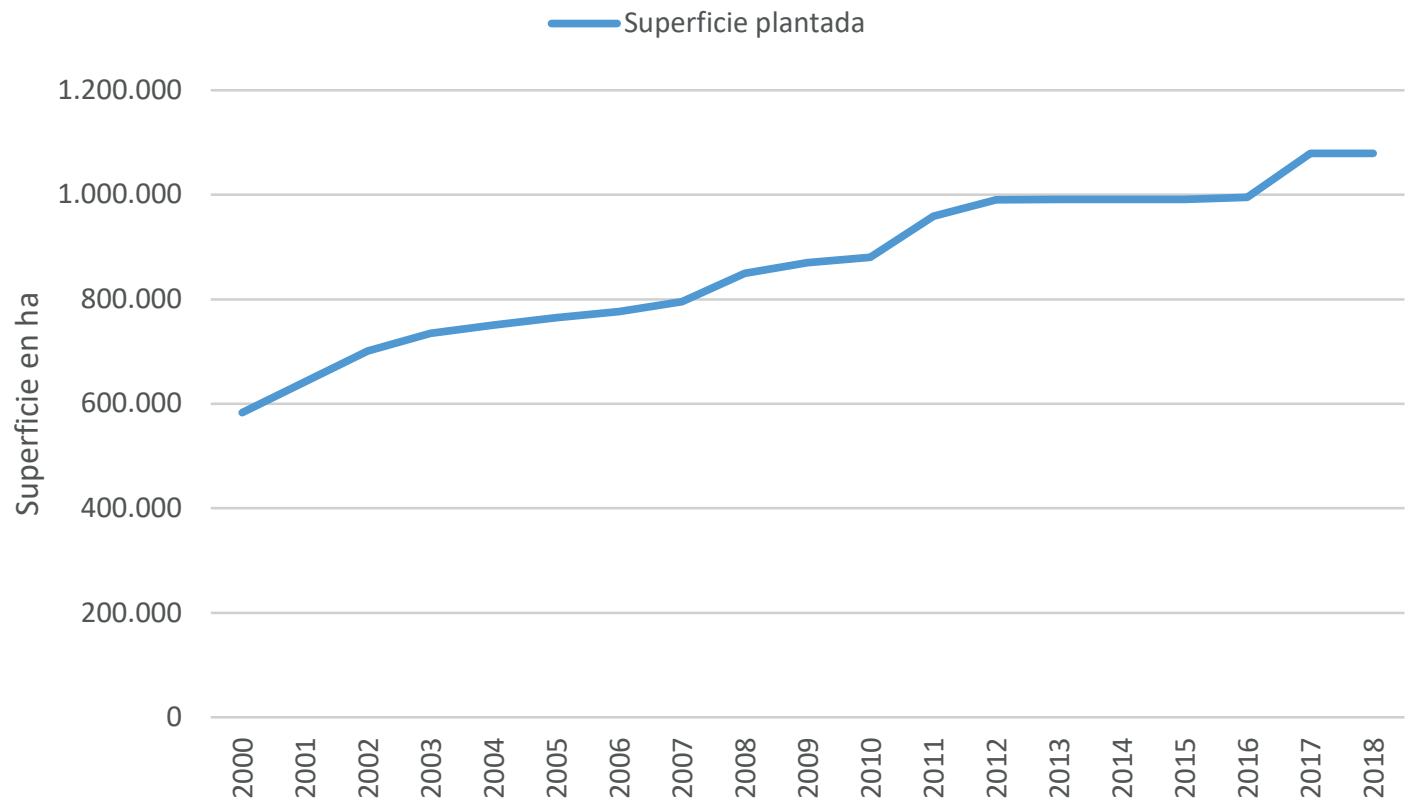

Fuente: Elaboración propia en base a Ministerio de Ganadería, Agricultura y Pesca (Anuarios DIEA, 2000 al 2019).

Las referidas transformaciones fueron motorizadas, en su mayor parte, por inversiones de empresas extranjeras tanto en la plantación como en la producción de pasta de celulosa, y, en menor medida, madera aserrada y tableros.

Desde el punto de vista manufacturero se distinguen, por un lado, la industria de la madera aserrada y, por otro, la de producción de celulosa. En este artículo, por ser una actividad reciente nos referiremos al segundo caso (Ministerio de Vivienda, Ordenamiento Territorial y Medio Ambiente Universidad de la República (ITU), 2019). 
Revista de Política Económica y Desarrollo Sostenible • EISSN: 2215-4167

Vol. 7 (1) • Julio-Diciembre, 2021: 1-34

DOI: https://doi.org/10.15359/peds.7-1.1

Bartesaghi y Silva

URL: http://www.revistas.una.ac.cr/politicaeconomica

Gráfico 8.

Extracción de madera en rollo (en metros cúbicos)

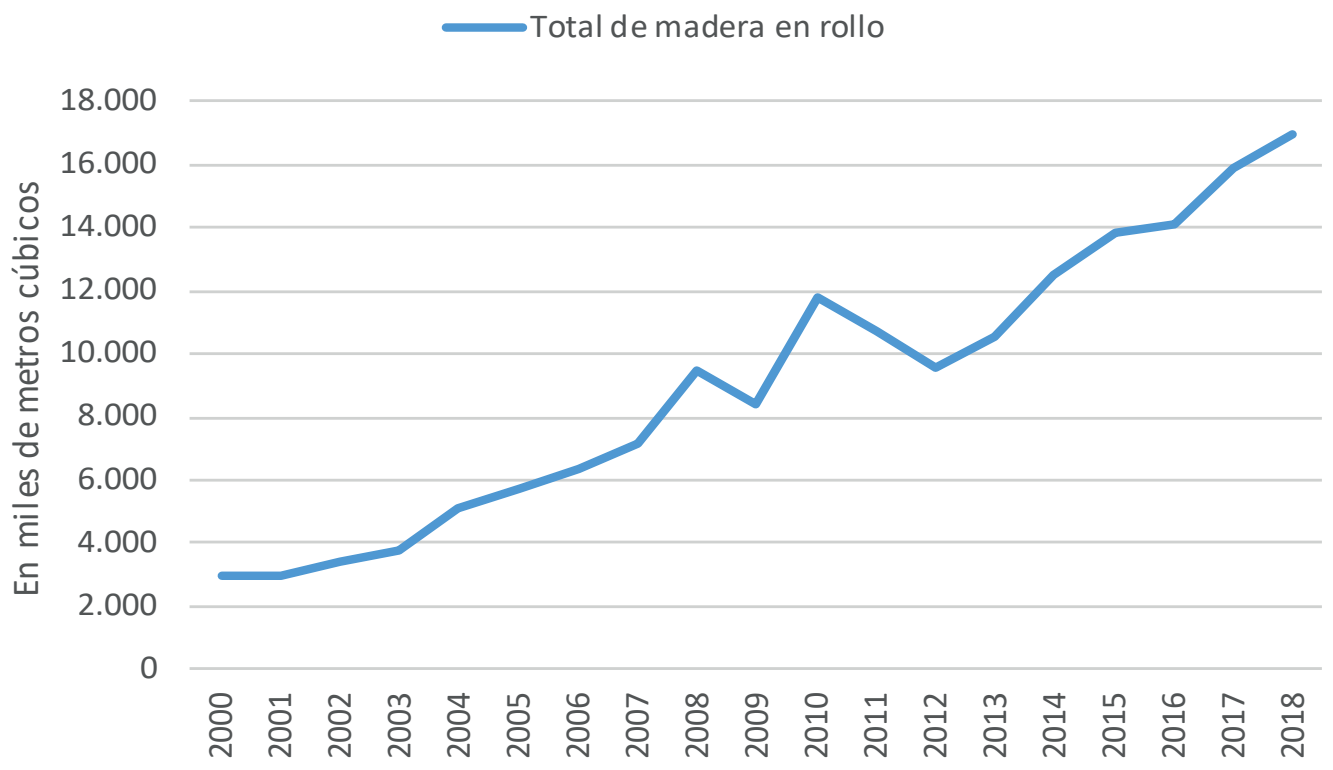

Fuente: Elaboración propia en base a Ministerio de Ganadería, Agricultura y Pesca

(Anuarios DIEA, 2000 al 2019).

Del total de madera extraída anualmente, un 38\% (medido en toneladas) se destina a la producción de celulosa. Dos empresas multinacionales lideran esta industria: UMP (originalmente denominada Botnia), instalada en el año 2005 en la ciudad de Fray Bentos (Río Negro), y Montes del Plata, instalada en la localidad de Conchillas (Departamento de Colonia). La primera de las fábricas procesa el $40 \%$ de los rollos destinados a celulosa; en tanto la segunda el 45\%. Un 13\% de la madera destinada a la industria se destina al chipeado en plantas instaladas en el área metropolitana de Montevideo.

Casi la mitad de la madera es provista por la zona litoral (principalmente por los departamentos de Río Negro y Paysandú); un 32\% proviene del este del país (departamentos de Maldonado, Rocha, Treinta y Tres) y un 25 de la región noreste (mayoritariamente desde los departamentos de Tacuarembó y Rivera).

Desde el punto de vista logístico la mayor parte de la madera se traslada por ruta (74\%), y se complementa vía fluvial con barcazas desde el litoral hacia la planta de Montes del Plata.

Las exportaciones de pasta de celulosa se realizan vía fluvial. UPM lo hace desde el puerto de Nueva Palmira (departamento de Colonia), previo traslado por el río Uruguay mediante barcazas hasta el puerto mencionado. En tanto, Montes del Plata realiza su embarque desde el propio puerto de la planta (Punta Pereira). 
Revista de Política Económica y Desarrollo Sostenible • EISSN: 2215-4167

Vol. 7 (1) • Julio-Diciembre, 2021: 1-34

DOI: https://doi.org/10.15359/peds.7-1.1

Bartesagbi y Silva

URL: http://www.revistas.una.ac.cr/politicaeconomica

En su conjunto, el complejo forestal representa un 16\% de la ocupación de las cadenas analizadas en este artículo, lo cual pone en evidencia la importancia social del sector. En la fase primaria ocupa en torno a 10.700 personas, en tanto que en la industria trabajan 8.600 personas (Ministerio de Vivienda, Ordenamiento Territorial y Medio Ambiente - Universidad de la República (ITU), 2019).

Cadena arrocera. Considerando las fases primarias e industrial, este sector representa el $11 \%$ de la producción de las cinco principales cadenas agroindustriales (Ministerio de Ganadería, Agricultura y Pesca, 2019). La región este del Uruguay produce el 72\%, en tanto las regiones noroeste y noreste el $19 \%$ y $9 \%$, respectivamente (gráfico 9).

En el período considerado, la superficie de arroz plantada no ha variado significativamente (gráfico 10). Por su parte, la producción y el rendimiento aumentaron 16\% y 23\%, lo cual evidencia un incremento de la productividad (Ministerio de Ganadería, Agricultura y Pesca, 2019).

Las plantas industriales se localizan, por costos asociados a la logística, en las áreas de producción primaria. La región este procesa el 52\% del arroz cosechado.

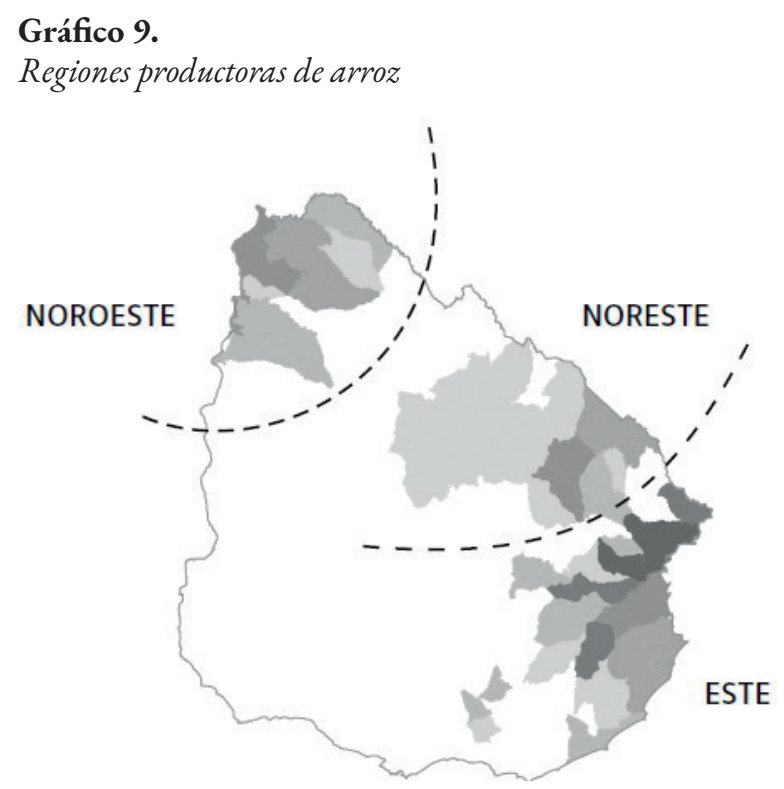

Fuente: Reproducido de Ministerio de Vivienda, Ordenamiento Territorial y Medio Ambiente Universidad de la República (ITU), (2019).

Luego de un período de intenso crecimiento entre los años 1970 y 2000 a una tasa de $6 \%$ anual, la producción de arroz ha demostrado en las dos últimas décadas un modesto crecimiento de menos de $1 \%$ anual. Las exportaciones son fundamentales para esta cadena. Uruguay exporta más del $90 \%$ de lo producido y participa del 3\% del mercado internacional. 
Revista de Política Económica y Desarrollo Sostenible • EISSN: 2215-4167

Vol. 7 (1) • Julio-Diciembre, 2021: 1-34

DOI: https://doi.org/10.15359/peds.7-1.1

Bartesaghi y Silva

URL: http://www.revistas.una.ac.cr/politicaeconomica

\section{Gráfico 10.}

Superficie de arroz sembrada, producción y rendimiento Periodo: zafras 2000/2001 -2018/2019

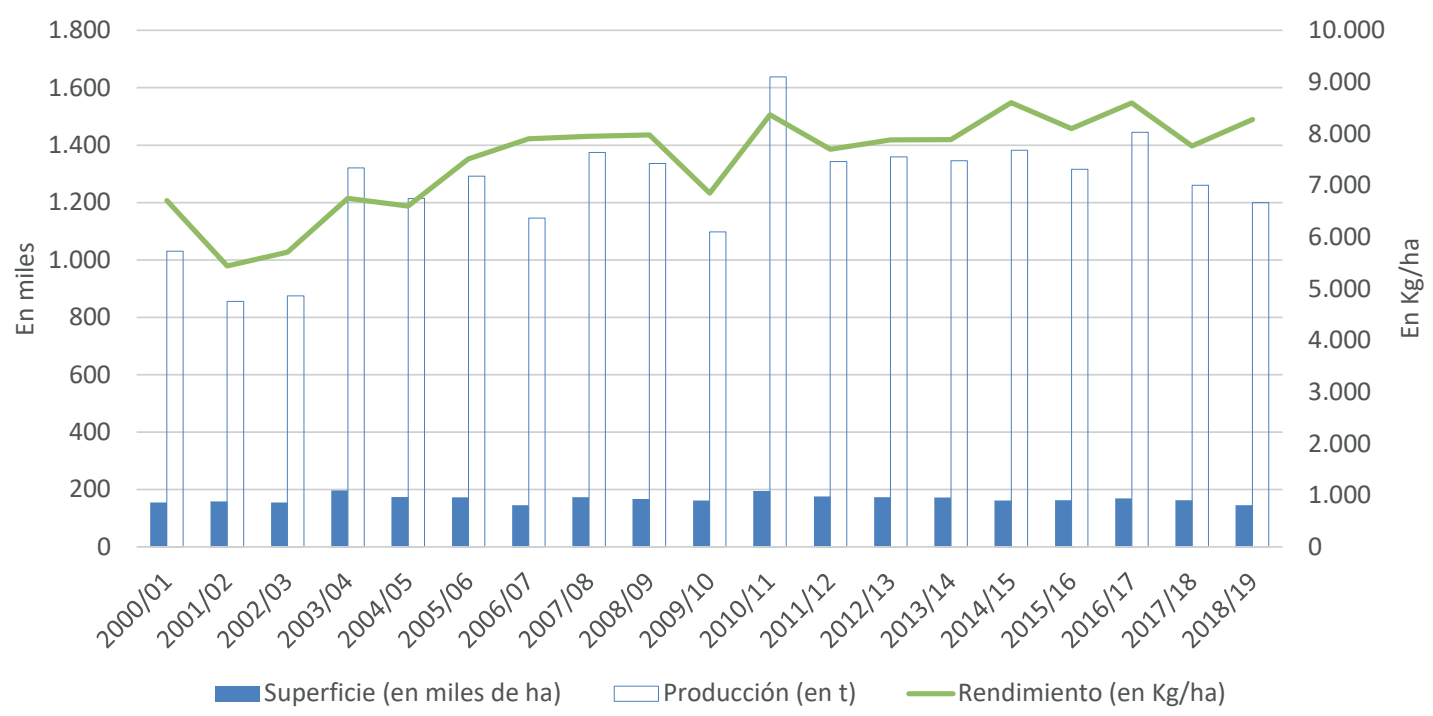

Fuente: Elaboración propia en base a Asociación de Cultivadores de Arroz (2020) y Ministerio de Ganadería, Agricultura y Pesca (2019).

Este sector productivo opera con un alto nivel de integración entre todos los actores participantes en las etapas de producción, industrialización y exportación. La Asociación de Cultivadores de Arroz (ACA) y la Gremial de Molinos Arroceros (GMA) son responsables de fijar un precio con base en los negocios concertados en el mercado mundial. Esto ofrece certezas tanto a productores como a industriales. Al mismo tiempo, y más allá de la fijación de precios, participan en esta cadena otras organizaciones que han contribuido con la mejora de la productividad y la eficiencia del sector, entre otras: el Instituto Nacional de Semillas (INASE), el Instituto Nacional de Investigación Agropecuaria (INIA), el Banco de la República Oriental del Uruguay (BROU) y el Estado generando políticas fiscales en tal sentido (Asociación de Cultivadores de Arroz, 2020).

La cadena arrocera uruguaya ha demostrado altos niveles de inversión e innovación que explican su importancia relativa a nivel mundial. Las inversiones por hectárea productiva figuran entre las más altas, y se destinan, entre otros insumos y tecnologías, a semilla, fertilizantes, herbicidas, combustibles, mano de obra, repuestos, agua, maquinaria y equipos, instalación de estaciones de bombeo, canales, drenajes, caminos, puentes, construcción de represas para riego (Ministerio de Vivienda, Ordenamiento Territorial y Medio Ambiente - Universidad de la República (ITU), 2019). A todo esto, hay que agregar la adopción de nuevas tecnologías para el cultivo y variedades de alto rendimiento desarrolladas a nivel nacional por el Instituto Nacional de Investigaciones Agropecuarias (INIA), que hoy constituyen el $90 \%$ de lo que se siembra. 
Revista de Política Económica y Desarrollo Sostenible • EISSN: 2215-4167

Vol. 7 (1) • Julio-Diciembre, 2021: 1-34

DOI: https://doi.org/10.15359/peds.7-1.1

Bartesaghi y Silva

URL: http://www.revistas.una.ac.cr/politicaeconomica

También en las últimas dos décadas se ha ampliado la capacidad para los procesos postcosecha e industrialización en infraestructuras tales como galpones, silos, secadores y molinos. La logística del transporte implica que todo el traslado desde la producción a los silos, plantas industriales o puntos de salida al exterior se realiza por carretera. Por el puerto de Montevideo se realiza el $81 \%$ de las exportaciones. El resto, con destino a los países vecinos, sale por Aceguá, Artigas, Chuy, Río Branco, Rivera y Salto (Asociación de Cultivadores de Arroz, 2020; Ministerio de Ganadería, Agricultura y Pesca, 2019).

Cadena láctea. La industria láctea representa el 6\% de la producción industrial del Uruguay y el valor agregado se estima en el 20\% (Ministerio de Vivienda, Ordenamiento Territorial y Medio Ambiente - Universidad de la República (ITU), 2019). Considerando las principales cadenas analizadas, la leche representa el $18 \%$ de la producción medida en toneladas. Si bien los tambos como unidad productiva están dispersos por todo el país, existen cuatro regiones importantes: suroeste, litoral, este y noreste. El suroeste (los departamentos de Florida, San José y Colonia) abastece el 80\% de la demanda de la leche para industria.

Más allá de problemáticas coyunturales, y visto en el plazo que analiza este artículo, esta cadena agroindustrial ha tenido un importante desarrollo. Entre otros factores, han sido importantes la innovación y el cambio técnico de los distintos componentes del proceso productivo (genética, alimentación, sanidad, etc.). También ha resultado importante la suplementación con granos, superando la tradicional alimentación pastoril. Por otra parte, nuevos actores de mediano y gran porte han incursionado en esta cadena productiva, algunos de ellos integrando las fases productivas e industrial a través de los denominados “megatambos” (Hernández, 2015).

Entre los años 2012 y 2018 la leche remitida a las plantas industriales pasó de 1,1 millones toneladas a 2,1 millones, incrementándose en más de un $80 \%$. Asimismo, los tres principales productos lácteos industrializados -leche en polvo, quesos y manteca y otras grasas- incrementaron en el mismo período su producción en $418 \%, 82 \%$ y 17\%, respectivamente (gráfico 11).

Por su parte, la estructura de participación de subproductos ha variado significativamente en el período considerado, tendiendo a una concentración en la leche en polvo como principal producto con casi el 70\% del total industrializado (Ministerio de Ganadería, Agricultura y Pesca 2014 y 2019). Entre tanto, la parcelación de quesos cayó del 39\% al 26\% entre 2000 y 2018, y la leche de media y larga vida descendió del $13 \%$ al $4 \%$.

En cuanto a la logística del transporte, la leche sin pasteurizar se traslada desde los tambos a las plantas industriales por carretera en camiones cisterna que cargan 21.000 litros (CSI Ingenieros y Steer Davies Glave, 2016). 
Revista de Política Económica y Desarrollo Sostenible • EISSN: 2215-4167

Vol. 7 (1) • Julio-Diciembre, 2021: 1-34

DOI: https://doi.org/10.15359/peds.7-1.1

Bartesaghi y Silva

URL: http://www.revistas.una.ac.cr/politicaeconomica

\section{Gráfico 11.}

Principales productos lácteos elaborados por año

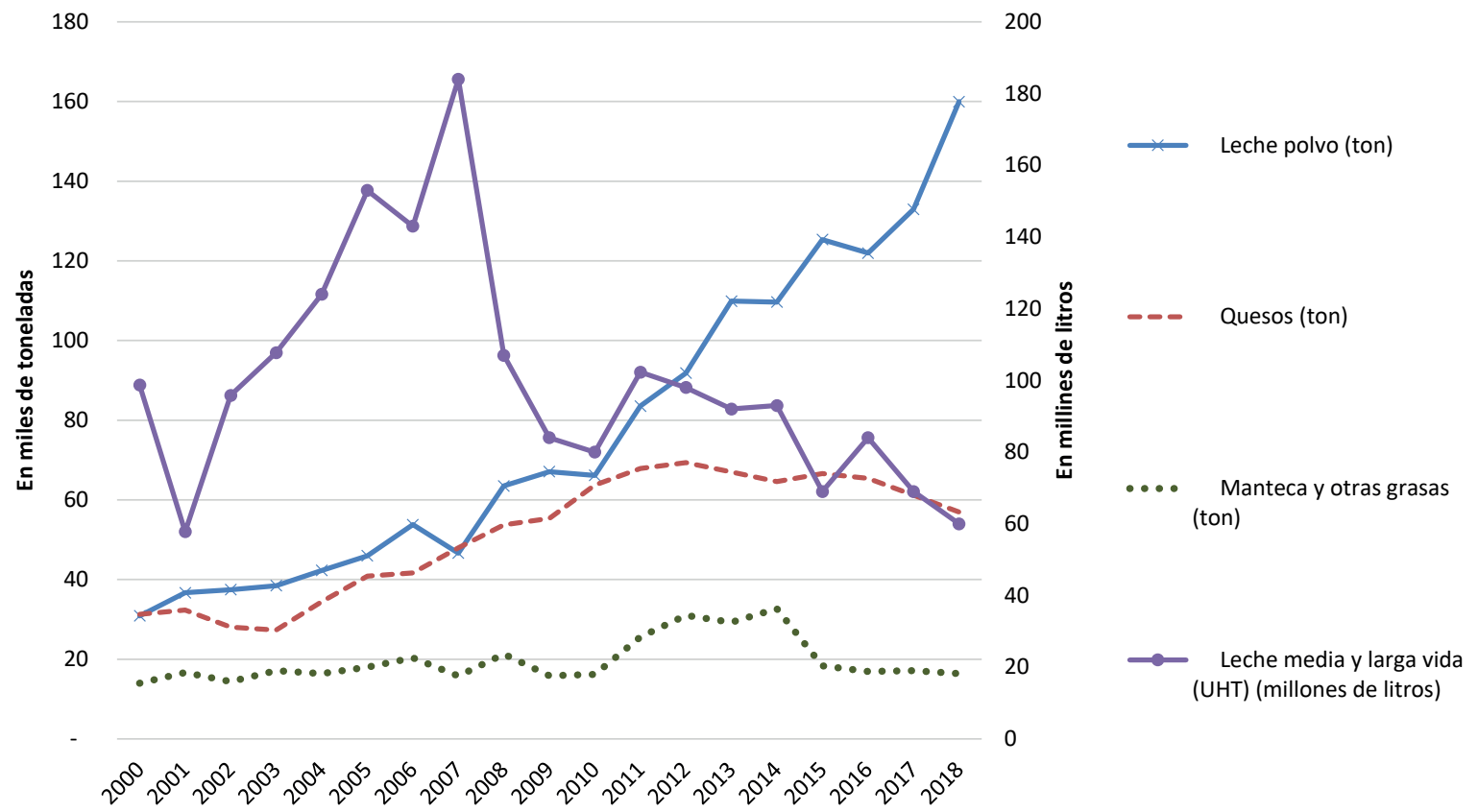

Fuente: Elaboración propia en base a Ministerio de Ganadería, Agricultura y Pesca (2005, 2010 y 2019).

El 70\% de la producción se destina a la exportación y la leche en polvo entera es el principal producto exportado. Las exportaciones se realizan en más de un 75\% por el puerto de Montevideo; en tanto el resto se exporta por carretera a la región del Mercosur, a través de los pasos fronterizos de Chuy, Fray Bentos, Paysandú, Río Branco, Rivera y Salto (Hernández, 2015).

\section{Comercio agroindustrial: una visión en conjunto de las cadenas}

Entre los años 2001 y 2019 las exportaciones totales del Uruguay pasaron de US\$2.058 millones a US\$ 7.816 millones, vale decir que tuvieron una variación del $280 \%$. Buena parte de este crecimiento ha estado centrado en el incremento de las exportaciones de bienes agroindustriales.

En el año 2001 los seis productos de base agraria más exportados, medidos en dólares, representaron un 38\% de las ventas totales del país. En el año 2019, este porcentaje ascendió al 56\%, lo que indica la profundización del modelo agroexportador del Uruguay y la concentración de la mayor parte de las exportaciones en pocos productos agroindustriales (Internacional Trade Centre, 2019).

El conjunto de los seis bienes más exportados ha cambiado su integración. A inicios de siglo XXI, los cueros y pieles de bovinos (partida 4101 del SA) y el arroz (partida 1006 del SA) eran los 
Revista de Política Económica y Desarrollo Sostenible • EISSN: 2215-4167

Vol. 7 (1) • Julio-Diciembre, 2021: 1-34

DOI: https://doi.org/10.15359/peds.7-1.1

Bartesagbi y Silva

URL: http://www.revistas.una.ac.cr/politicaeconomica

productos agroindustriales que generaban los mayores ingresos por concepto de exportaciones. La lana (partida 5105 del SA) y la malta de cebada u otros cereales (partida 1107 del SA) también figuraban entre este grupo (Gráfico 12).

Gráfico 12.

Principales productos exportados en el año 2001 (sin zonas francas)

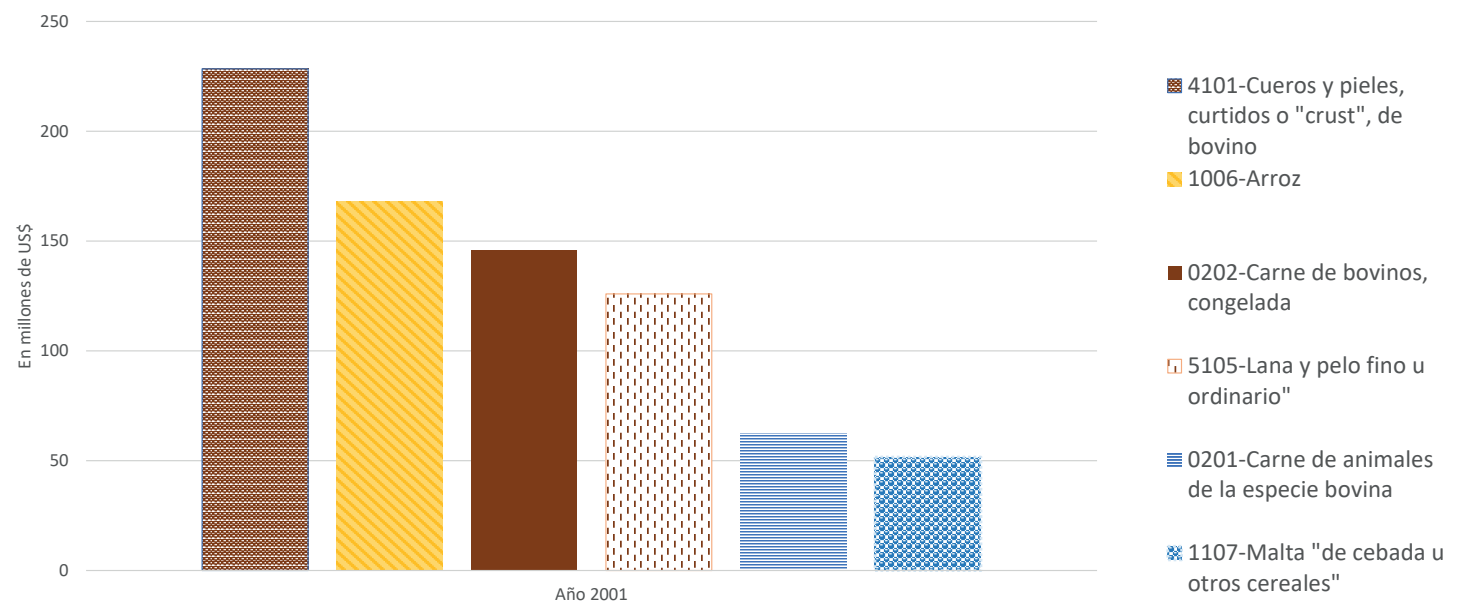

Fuente: Elaboración propia en base a Internacional Trade Centre (2019).

Con el correr de las dos últimas décadas, la matriz agroexportadora cambió sustancialmente. La carne de bovinos congelada (partida 0202 del SA), las habas de soja (partida 1201 del SA) y la madera en bruto (partida 4403 del SA) se posicionaron como los bienes de base agraria más exportados. También la leche y nata "crema" (partida 0402 del SA) se integraron al top de los seis bienes más exportados (gráficos 13 y 14). Por su parte, perdieron importancia relativa los cueros y pieles de bovinos (partida 4101 del SA) y la lana (partida 5105 del SA). La malta de cebada u otros cereales (partida 1107 del SA), aunque disminuyó sus ventas en menor proporción, también dejó de figurar entre los seis productos más exportados. 
Revista de Política Económica y Desarrollo Sostenible • EISSN: 2215-4167

Vol. 7 (1) • Julio-Diciembre, 2021: 1-34

DOI: https://doi.org/10.15359/peds.7-1.1

Bartesaghi y Silva

URL: http://www.revistas.una.ac.cr/politicaeconomica

\section{Gráfico 13.}

Principales productos exportados en el año 2019 (sin zonas francas)

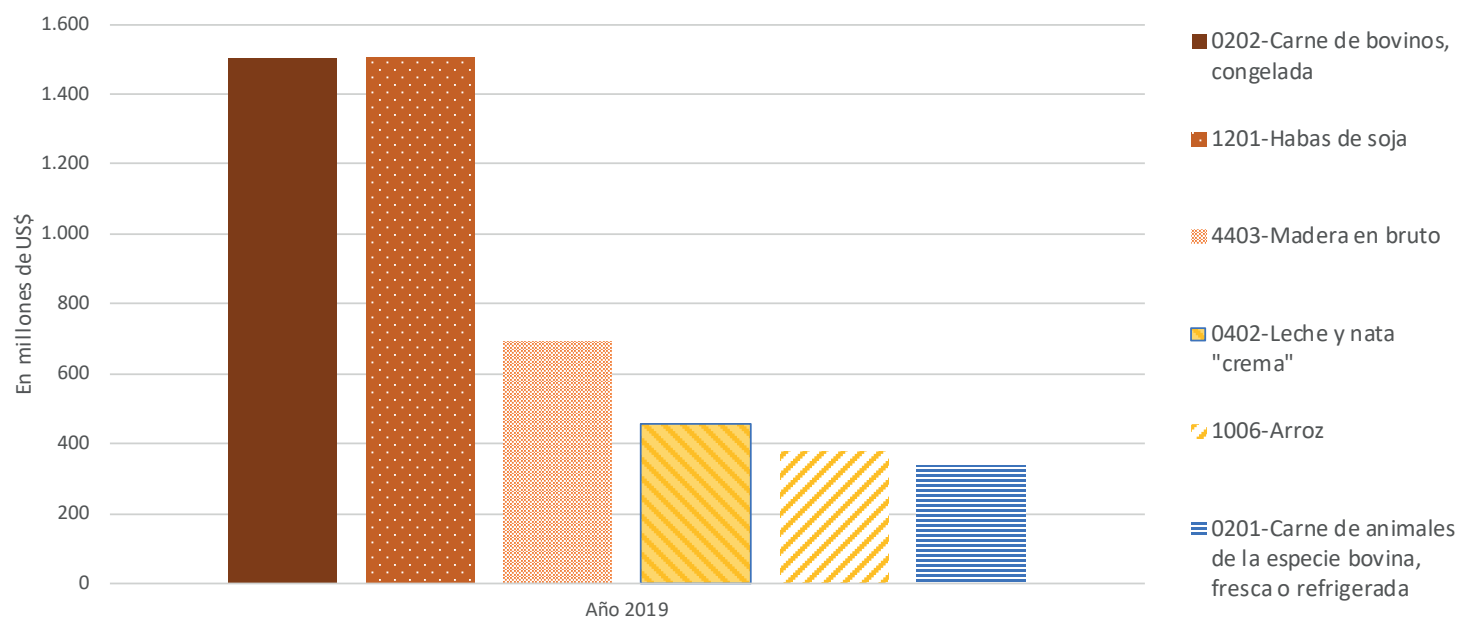

Fuente: Elaboración propia en base a Internacional Trade Centre (2019).

Gráfico 14.

Evolución de las exportaciones de arroz, carne bovina, lácteos y soja (en U\$S). Periodo 2000-2019

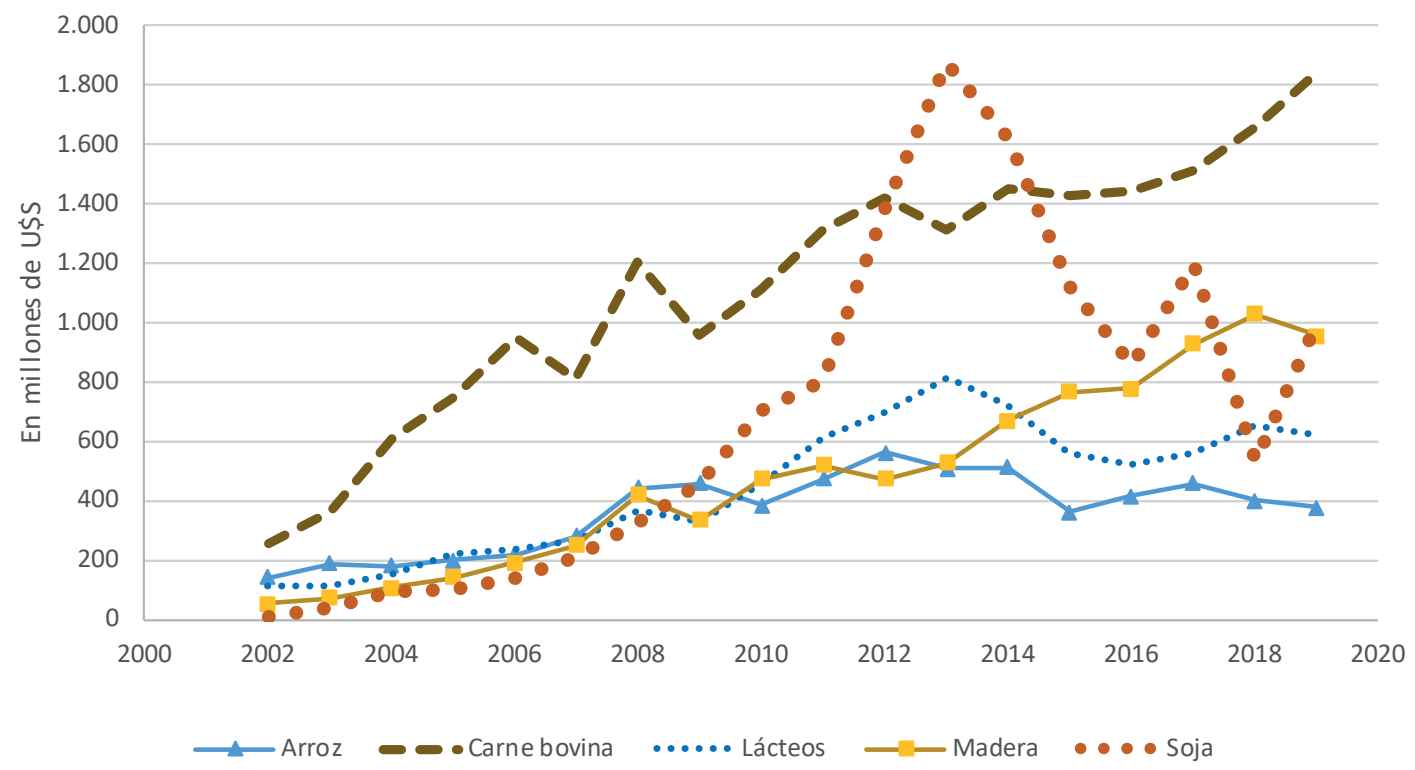

Fuente: Elaboración propia en base a Internacional Trade Centre (2019). 
Revista de Política Económica y Desarrollo Sostenible • EISSN: 2215-4167

Vol. 7 (1) • Julio-Diciembre, 2021: 1-34

DOI: https://doi.org/10.15359/peds.7-1.1

Bartesagbi y Silva

URL: http://www.revistas.una.ac.cr/politicaeconomica

Si bien los dos principales productos de exportación de Uruguay provienen de la carne bovina y de la soja, son los productos derivados de la madera y de la soja los que han registrado las mayores variaciones desde inicio del presente siglo. La soja ha registrado una variación notable, en casi dos décadas; en tanto el arroz y los lácteos, comparativamente, han variado en mucho menor porcentaje (gráfico 15).

Otros cambios importantes registrados tienen que ver con los clientes de Uruguay. A inicios de la década de los 2000, la región (Brasil y Argentina) adquirían un tercio de la producción agropecuaria nacional. Actualmente, China es el principal comprador con el $27 \%$ de las importaciones de origen uruguayo, en tanto Brasil importa en el presente alrededor del 14\% (gráficos 16 y 17). Vale decir, Uruguay ha incrementado sus exportaciones fuera de la región del Mercosur, a pesar de no contar con acuerdos comerciales con los clientes más importantes que tiene el país en la actualidad.

\section{Gráfico 15.}

Variaciones porcentuales de exportaciones de madera, soja, lácteos, carne bovina y arroz (periodo 2002-2019)

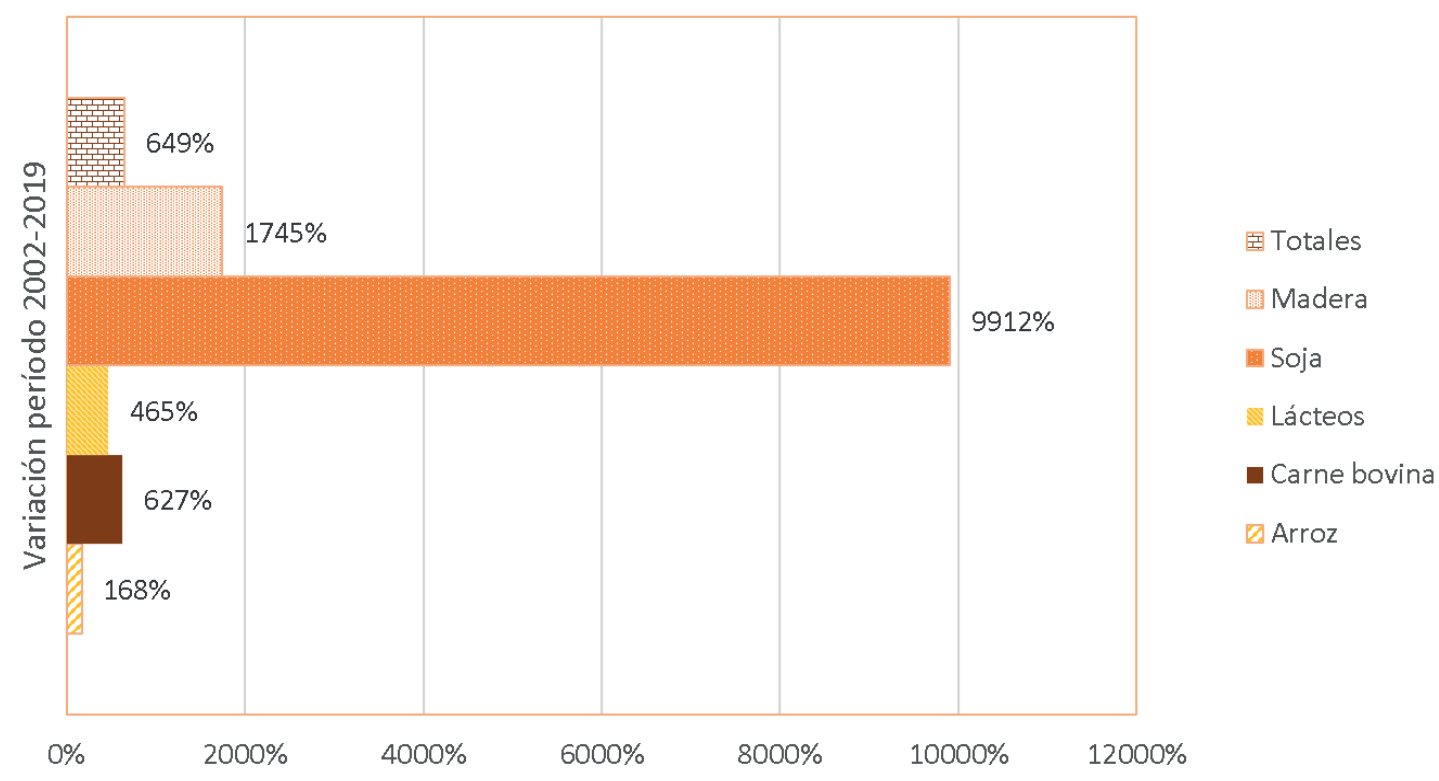

Fuente: Elaboración propia en base a Internacional Trade Centre (2019). 
Revista de Política Económica y Desarrollo Sostenible • EISSN: 2215-4167

Vol. 7 (1) • Julio-Diciembre, 2021: 1-34

DOI: https://doi.org/10.15359/peds.7-1.1

Bartesaghi y Silva

URL: http://www.revistas.una.ac.cr/politicaeconomica

\section{Gráfico 16.}

Principales mercados importadores de productos de base agraria de Uruguay

Año 2001

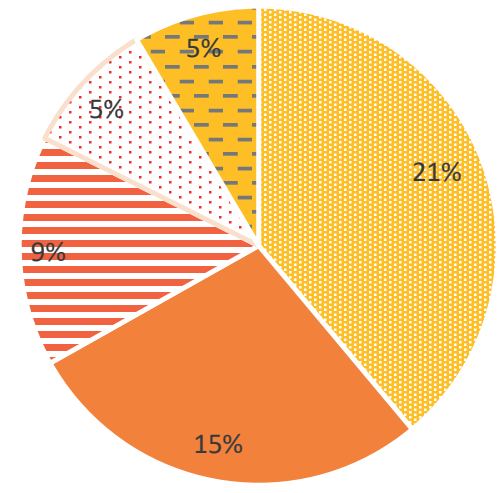

: Brasil

- Argentina

- Estados Unidos de América

- China

๓ Alemania

Fuente: Elaboración propia en base a Internacional Trade Centre (2019).

\section{Gráfico 17.}

Principales mercados importadores de productos de base agraria de Uruguay

Año 2019

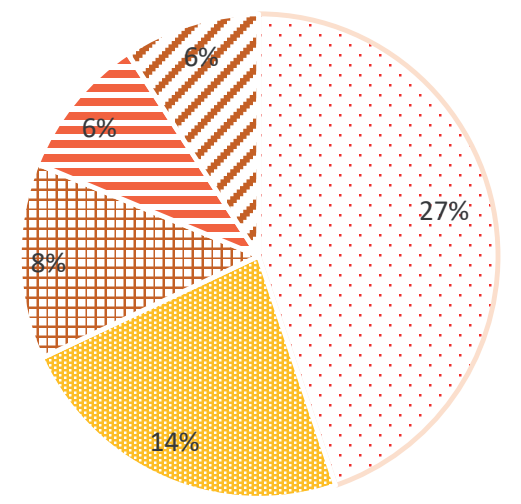

$$
\begin{aligned}
& \text {. China } \\
& \text { \# Brasil } \\
& \text { + Zona Nep } \\
& \text { = Estados Unidos de América } \\
& \text { Zona franca }
\end{aligned}
$$

Fuente: Elaboración propia en base a Internacional Trade Centre (2019). 
Revista de Política Económica y Desarrollo Sostenible • EISSN: 2215-4167

Vol. 7 (1) • Julio-Diciembre, 2021: 1-34

DOI: https://doi.org/10.15359/peds.7-1.1

Bartesaghi y Silva

URL: http://www.revistas.una.ac.cr/politicaeconomica

\section{Consideraciones finales}

A lo largo de este artículo se pusieron en evidencia las importantes transformaciones en materia de producción de base agrícola y el desarrollo del comercio mundial de estos productos. Al mismo tiempo, se hizo un análisis de las principales cadenas agroproductivas de Uruguay, las cuales constituyen los pilares económicos del país, por la dinámica interna que generan y por ser las principales fuentes de ingresos de divisas por concepto de exportaciones.

Diversas son las causas que han provocado un acelerado crecimiento de la producción y el comercio de productos de base agraria. Los países emergentes han sido clave en este proceso, lo cual ha derivado en un reposicionamiento geoeconómico y geopolítico de estos en el concierto internacional.

El incremento del poder adquisitivo, el crecimiento demográfico de algunas regiones y la tendencia acelerada a la urbanización de la población mundial están en la base de estos fenómenos.

En general, tanto la producción como el comercio de base agraria han crecido en los últimos veinte años a tasas superiores que la población mundial. De ninguna manera quiere decir que todo el planeta se ha beneficiado por igual de la disponibilidad de alimentos, por ejemplo; ni que el sistema de comercio internacional sea justo y transparente. Algunos de los países menos adelantados (PMA) siguen teniendo serias dificultades para satisfacer los niveles básicos de seguridad alimentaria, $\mathrm{y}$, en muchos casos, son altamente dependientes de la solidaridad internacional.

En este proceso de incremento de la producción y de la oferta agroindustrial, el Mercosur ha sido un actor clave, y probablemente lo siga siendo por mucho tiempo. Dentro del bloque, Brasil se ha posicionado como una potencia agroalimentaria, y se encuentra en pleno proceso de expansión productiva y comercial.

Uruguay, luego de haber atravesado una severa crisis económica a inicios del siglo XXI, se insertó aceleradamente en este proceso de expansión de demanda y comercio mundiales, en base a productos tradicionales para el país (carne bovina, lácteos, arroz) y también a nuevas actividades agroproductivas que cobraron vigor en el presente siglo, como la soja y la forestación. Estas nuevas cadenas, entre otros efectos asociados, implicaron una reconfiguración de la producción en el espacio. En términos generales, los mejores suelos fueron destinados a la producción agrícola (por ejemplo, en el litoral suroeste), y los de menor calidad fueron asumidos tanto por la ganadería como por la forestación.

Uruguay puso en práctica en el año 2005 un programa de desarrollo productivo que, si bien continuó con algunos aspectos de planes anteriores, puso énfasis en la captación de IED a través de la implementación de zonas francas y la aprobación de una Ley de Inversiones, que generaron las condiciones propicias para el desarrollo de las cadenas analizadas y la expansión de las exportaciones, principalmente hacia China y Brasil. En general se ha tratado de un modelo que apuntó a la reprimarización de la economía con cadenas poco extensas y de valor agregado de bajo a medio, dependiendo del sector.

La innovación en la gestión del negocio agropecuario y la tecnificación en la producción 
Revista de Política Económica y Desarrollo Sostenible • EISSN: 2215-4167

Vol. 7 (1) • Julio-Diciembre, 2021: 1-34

DOI: https://doi.org/10.15359/peds.7-1.1

Bartesaghi y Silva

URL: http://www.revistas.una.ac.cr/politicaeconomica

primaria, entre otros factores, han permitido al mismo tiempo importantes niveles de competitividad de la producción uruguaya, que ha logrado, incluso, sortear los altos costos productivos y ciertas carencias logísticas que tiene el país. Buena parte de estos cambios fue impulsada por capitales transnacionales instalados en el país, al amparo de los mencionados incentivos junto a la seguridad jurídica y la estabilidad sociopolítica.

Existen desafíos importantes como lo son, entre otros, avanzar en la industrialización de la producción sojera, así como también iniciar un proceso de equilibrio en la matriz agroexportadora, ya que una parte mayoritaria de las ventas al exterior se ha ido concentrado en muy pocos productos y destinos.

Al mismo tiempo, Uruguay tiene pendiente renegociar aspectos que flexibilicen el acuerdo del Mercosur y le permitan, a la vez, avanzar en acuerdo bilaterales o regionales con sus principales socios comerciales. En tal sentido, el acuerdo con la Unión Europea abre una ventana de oportunidades importante en tal sentido, más allá de los desafíos que aún se deben sortear dentro de cada bloque negociador.

\section{Referencias}

Achkar, M., Domínguez, A. \& Pesce, F. (2006). Principales transformaciones territoriales en el Uruguay contemporáneo. Santa Fe, Rep. Argentina: UNL-UDELAR.

Achkar, M., Domínguez, A. \& Pesce, F. (2008). Complejidad, diversidad y transformaciones en nuestros ecosistemas y territorios. Quebacer educativo, XVIII(90), 33-38.

Aguirre, E. (2020). Evolución reciente de la productividad ganadera en Uruguay (2010-17). Metodología y primeros resultados. Montevideo: Anuario OPYPA.

Arbeletche P. \& Carballo, C. (2006 .). Crecimiento agrícola y exclusión: el caso de la agricultura de secano en Uruguay. VII Congreso Latinoamericano de Sociología Rural (ALASRU). Quito.

Asociación Cultivadores de Arroz (15 de febrero de 2020). Asociación Cultivadores de Arroz. http:// www.aca.com.uy/

Banco Interamericano de Desarrollo. Consultor Gonzalo Manrique (2011). Manual de cadenas de valor agropecuarias. Washington, D.C.: BID.

Bértola, L. (2018a). 50 años de historia de la OPP. Montevideo: Fin de Siglo.

Bértola, L. (2018b). El panorama de las politicas de desarrollo productivo en Uruguay. Lima: OIT Américas, Informes Técnicos.

Blum, A., Narbondo, I. \& Oyhantcabal, G. (2008). ¿Dónde nos lleva la soja? Sojización a la uruguaya: principales impactos socioambientales. Montevideo: RAP-AL Uruguay. 
Revista de Política Económica y Desarrollo Sostenible • EISSN: 2215-4167

Vol. 7 (1) • Julio-Diciembre, 2021: 1-34

DOI: https://doi.org/10.15359/peds.7-1.1

Bartesagbi y Silva

URL: http://www.revistas.una.ac.cr/politicaeconomica

Bolsa de Cereales de Entre Ríos (2014). Estadísticas. http://www.bolsacer.org.ar/Fuentes/estadisticas.php

Canta, A., Casabella, R., Conde, O., Cordiano, M., Roselló, J.M. \& Torres, G. (2014). Comercio internacional en el siglo XXI, la puerta de acceso a los negiocios globales. Buenos Aires: Dunken.

Carreño, C. \& Alfonso, W. (2018). Relación entre los procesos de urbanización, el comercio internacional y su incidencia en la sostenibilidad urbana. Cuadernos de Vivienda y Urbanismo, 11(22), 2-12.

Ciani, R., Reus, A. \& Aramayo, M. (2018). Destino de la producción de soja argentina. Buenos Aires: Subsecretaría de Mercados Agropecuarios.

Consejo Agropecuario del Sur (CAS) (2017). Anuario de comercio exterior de base agraria de los paises del CAS, 2013-2017. CAS.

CSI Ingenieros y Steer Davies Glave. (2016). Estudio de Demanda y Modelo de Asignación Modal de Transporte Interurbano de Carga en Uruguay. Montevideo: Ministerio de Transporte y Obras Públicas.

De los Campos G. \& Pereira, G. (5 de noviembre de 2019). La actividad agricola de secano en el Uruguay. http://www.rau.edu.uy/agro/ccss/publicaciones/Publicaciones_en_Adobat/03 Actividad_\%20agricola_secano.pdf

Departamento de Negocios Internacionales e Integración (DNII) (2019). Comercio Exterior de Uruguay - Noviembre de 2019. Montevideo: Universidad Católica del Uruguay.

Dirección Nacional de Medio Ambiente-Uruguay (2014). Indicadores ambientales. http://www. dinama.gub.uy/IndicadoresWeb/

FAO (2018). El estado de los mercados de productos básicos agricolas 2018. El comercio agricola, el cambio climático. Roma: Organización de las Naciones Unidas para la Alimentación.

FAO (12 de Diciembre de 2019). FAOSTAT. http://www.fao.org/faostat/es/\#data/QC

FAO (15 de enero de 2020). Organización de las Naciones Unidad para para la Alimentación y la Agricultura-FAO. http://www.fao.org/dairy-production-products/production/es/

Grupo de Ecología del Paisaje y del Medio Ambiente (2015). Atlas del agronegocio. Datos y hechos sobre la industria agricola y de alimentos. Berlín: Fundación Heinrich Böll.

Guibert, M., Grosso, S., Arbeleche, P. \& Bellini, E. (2011). De Argentina a Uruguay: espacios y actores de una nueva lógica de producción agrí́cola. Pampa, 07, 13-38.

Gutiérrez, G. (2009). Análisis de cadenas basadas en la producción de granos de secano para la definición de lineamientos de politicas específicas. Montevideo: FAO. 
Revista de Política Económica y Desarrollo Sostenible • EISSN: 2215-4167

Vol. 7 (1) • Julio-Diciembre, 2021: 1-34

DOI: https://doi.org/10.15359/peds.7-1.1

Bartesaghi y Silva

URL: http://www.revistas.una.ac.cr/politicaeconomica

Harvey, D. (2003). Espacios de esperanza. Madrid: Akal.

Hernández, A. (2015). Producción animal: Lechería comercial. Año 2014 . Montevideo: Ministerio de Ganadería, Agricultura y Pesca. Dirección de Estadísticas Agropecuarias (DIEA), Anuario Estadístico Agropecuario 2015.

Instituto Interamericano de Cooperación para la Agricultura (IICA) (2007). La contribución al IICA a la agricultura y al desarrollo de las comunidades rurales del Uruguay. Montevideo: IICA.

Instituto Nacional de Carnes-INAC (2018). Anuario Estadístico 2017. Montevideo: INAC.

Internacional Trade Centre (5 de diciembre de 2019). Trade Map. https://www.trademap.org/Index.aspx

Ministerio de Ganadería, Agricultura y Pesca de Argentina (14 de noviembre de 2019). Subsecretaría de Alimentos y Bebidas. http://www.alimentosargentinos.gob.ar/HomeAlimentos/Publicaciones/ revistas/nota.php?id=187

Ministerio de Ganadería, Agricultura y Pesca (2014). Estadísticas Agropecuarias. Series históricas. Montevideo: MGAP.

Ministerio de Ganadería, Agricultura y Pesca (3 de noviembre de 2019). Dirección General de Servicios Agricolas. http://www.mgap.gub.uy/unidad-organizativa/direccion-general-de-serviciosagricolas/plan-nacional-de-silos/infraestructura-de-almacenaje

Ministerio de Ganadería Agricultura y Pesca-DIEA (25 de diciembre de 2019). Anuario Estadístico Agropecuario 2005. http://www.mgap.gub.uy/unidad-organizativa/oficina-de-programacion-ypoliticas-agropecuarias/publicaciones/anuarios-diea

Ministerio de Ganadería, Agricultura y Pesca-DIEA (5 de noviembre de 2019). Anuario Estadístico 2019. http://www.mgap.gub.uy/unidad-organizativa/oficina-de-programacion-y-politicasagropecuarias/publicaciones/anuarios-diea

Ministerio de Vivienda, Ordenamiento Territorial y Medio Ambiente-Universidad de la República (ITU) (2019). Lógicas territoriales del uruguay agroexportador. Montevideo: Facultad de Arquitectura, Diseño y Urbanismo (FADU) .

Oficina de Planeamiento y Presupuesto-Presidencia de la República (2009). Estrategia Uruguay III siglo. Montevideo: OPP.

Otero, M. \& Larios, J.F. (1999). La industrialización de la agricultura: riesgos y desafíos para América Latina frente a la globalización y la apertura. Agroalimentaria, 73-77.

Oyhantcabal, G. \& Narbondo, I. (2011). Radiografía del negocio sojero. Descripción de los principales actores y de los impactos socio-económicos en el Uruguay. Montevideo: Redes AT. 
Revista de Política Económica y Desarrollo Sostenible • EISSN: 2215-4167

Vol. 7 (1) • Julio-Diciembre, 2021: 1-34

DOI: https://doi.org/10.15359/peds.7-1.1

Bartesaghi y Silva

URL: http://www.revistas.una.ac.cr/politicaeconomica

Perrotti, D. (2015). La República Popular de China y América Latina: impacto del crecimiento económico chino en las exportaciones latinoamericanas. Revista CEPAL, 116, 47-60.

Picado, W. (2008). Ciencia y geopolítica en los orígenes de la Revolución Verde. Revista de Ciencias Ambientales, 36(1), 46-56.

Pou, R. (2013). Uruguay Forestal 2012. Rosario: Rosario Pou \& Asociados. Inversores Forestales.

Revista Énfasis (21 de agosto de 2015). ¿Es India el mayor exportador de carne bovina? http://www. alimentacion.enfasis.com/notas/73061-es-india-el-mayor-exportador-carne-bovina-

Ribeiro J. y Fornazier, A. (2016). Productividad agropecuaria: reducción de la brecha productiva entre el Brasil y los Estados Unidos de América. Revista CEPAL 118, CEPAL.

Torres, S. (2019). Uruguay: Perfil económico-productivo, desafíos para la transformación socioecológica. Análisis, 23, 3-69.

Últimas Noticias (16 de junio de 2010). Llegada de productores argentinos triplicó precio de campos para soja. http://www.ultimasnoticias.com.uy/hemeroteca/160610/prints/eco02.html.

Umberger, W. (2015). Demographic Trends: Implications for Future Food Demand. Agricultural Symposium. Federal Reserve Bank of Kansas City (págs. 1-16). Kansas City: Federal Reserve Bank of Kansas City.

USDA (22 de febrero de 2020). United States Department of Agriculture. World Agricultural Production. Estados Unidos: USDA. https://downloads.usda.library.cornell.edu/usda-esmis/ files/5q47rn72z/xd07h985g/j098zv39s/production.pdf. 